\title{
RobertoCasanovaDinato
}

Variáveis biomecânicas relacionadas ao impacto e percepção de conforto em calçados de corrida com diferentes tecnologias de amortecimento

Dissertação apresentada a Faculdade de Medicina da Universidade de São Paulo para obtenção do título de Mestre em Ciências.

Programa de Ciências da Reabilitação.

Área de Concentração: Movimento, Postura e Ação Humana.

Orientadora: Profa. Dra. Isabel de Camargo Neves Sacco

São Paulo 


\title{
RobertoCasanovaDinato
}

\section{Variáveis biomecânicas relacionadas ao impacto e percepção de conforto em calçados de corrida com diferentes tecnologias de amortecimento}

\author{
Dissertação apresentada a Faculdade de Medicina \\ da Universidade de São Paulo para obtenção do \\ título de Mestre em Ciências. \\ Programa de Ciências da Reabilitação. \\ Área de Concentração: Movimento, Postura e \\ Ação Humana. \\ Orientadora: Profa. Dra. Isabel de Camargo \\ Neves Sacco
}

(Versão corrigida - Resolução CoPGr 6018 de 13 de Outubro de 2011. A versão original esta disponível na biblioteca da FMUSP)

\section{São Paulo}


Dados Internacionaîs de Catalogação na Pub licação (CIP)

Ereparada pela Biblioteca da

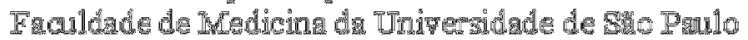

Ereproducio antorizada pelo mutor

Dimato, Roberto Casanova

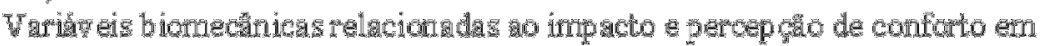
calcados de corrida com diferentes tecnologias de anotecimento / Robetho

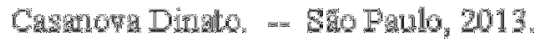

Discraço(mestrado-Faculdade de Medicina da Onirendade de sa Paulo.

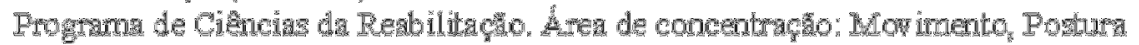
e Ação Humana.

Orientadcra: Isabel de Canargo Her Sacco.

Descritores: 1. Corrida 2.Sapiatos 3.Biomecânica 4. Pressüo 5.Cinética

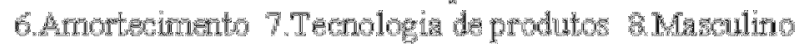

TISPIFMDBD-128/13 
Dedico este trabalho a minha esposa Luana e ao meu filho Lucas.

A meus pais e irmãs.

E a todos que contribuíram direta ou indiretamente. 


\section{AGRADECIMENTOS}

Este trabalho só foi possível graças à orientação da Profa. Isabel Sacco que abriu as portas do laboratório para que eu pudesse aprender biomecânica através de seus ensinamentos. Sempre com uma personalidade forte e exigente, me mostrou o caminho da produção científica e o exemplo de como me fortalecer na busca pela docência, além de acreditar no meu potencial e me dar à oportunidade de desenvolver este projeto.

Agradeço de forma especial, aos amigos Ana Paula pelas valiosas contribuições nas revisões dos artigos, à Ivye pela ajuda nas coletas, ao Kenji pela valiosa ajuda no desenvolvimento das rotinas e ao Francis pelas pontuais ajudas nas análises estatísticas.

A todos os companheiros de laboratório, Franklin, Adriana, Naomi, Ricky, Cristina, Anice, Alessandra, Mariane, Andreja, Licia e Vitor, que através de conversas descontraídas contribuíram para o resultado final deste trabalho. Sinto-me honrado em ter participado de um grupo tão talentoso e competente.

Aos professores Dr. Marcos Duarte, Dr. Paulo Roberto e Dra. Paula Lobo pelas preciosas contribuições feitas no exame de qualificação.

A todos os corredores que participaram voluntariamente das coletas e principalmente à CORPORE - Corredores Paulistas Reunidos, através de seu representante Sr. Edgar, pelo auxilio na divulgação deste projeto junto aos corredores. 
A empresa Dass Sul Indústria e Comércio de Artigos Esportivos Ltda., pelo fornecimento dos calçados esportivos e pelo teste mecânico dos calçados.

A FAPESP - Fundação de apoio à pesquisa do estado de São Paulo, pela bolsa concedida, possibilitando minha dedicação integral ao mestrado (processo número 2010/14044-1).

E Finalmente, exalto o apoio sempre incondicional da minha esposa Luana pela compreensão, paciência, suporte emocional e financeiro durante todo esse tempo. Sempre de forma lúcida e tranqüila, me transmitiu confiança para seguir em frente. E agradeço acima de tudo, por ter nos dado o bem mais precioso de nossas vidas, nosso filho Lucas. Também de forma especial, a minha mãe, meu pai e minhas irmãs. A todos muito obrigado. 
Quando você quer muito alguma coisa,

todo o universo conspira para que você

realize seu desejo.

Paulo Coelho 


\section{NORMALIZAÇÃO ADOTADA}

Esta dissertação ou tese está de acordo com as seguintes normas, em vigor no momento destapublicação:

Referências: adaptado de International Committee of Medical Journals Editors (Vancouver).

Universidade de São Paulo. Faculdade de Medicina. Divisão de Biblioteca e Documentação. Guia deapresentação de dissertações, teses e monografias. Elaborado por Anneliese Carneiro da Cunha, Maria Julia de A. L. Freddi, Maria F. Crestana, Marinalva de Souza Aragão, Suely Campos Cardoso,Valéria Vilhena. 3a ed. São Paulo: Divisão de Biblioteca e Documentação; 2011.

Abreviaturas dos títulos dos periódicos de acordo com List of Journals Indexed in Index Medicus. 


\section{SUMÁRIO}

Lista de siglas

Lista de tabelas

Lista de figuras

\section{Resumo}

\section{Summary}

1 INTRODUÇÃ $O$

1.1 CONTEXTUALIZAÇÃO DO PROBLEMA DE PESQUISA …..................................... 1

1.2 ESTRUTURA E CONSTRUÇÃO DO CALÇADO ESPORTIVO ................................. 5

1.3 AvaliaÇÕES BIOMECÂNICAS DE CALÇAdOS ESPORTIVOS ........................... 8

1.4 AVALIAÇÃO DO CONFORTO DE CALÇADOS ESPORTIVOS E SUA RELAÇÃO COM

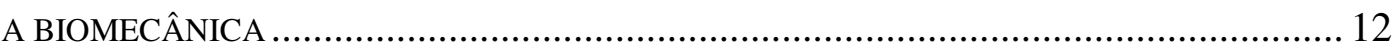

2 OBJETIVOS

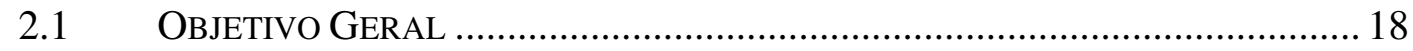

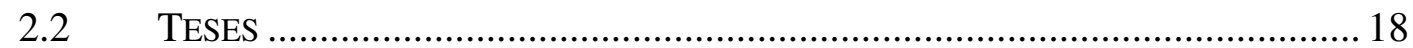

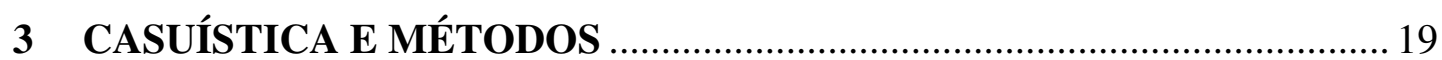

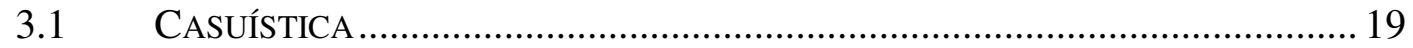

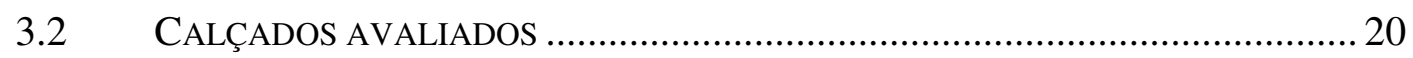

3.3 AVALIAÇÃO EM CAMPO - ETAPA I ..................................................... 23

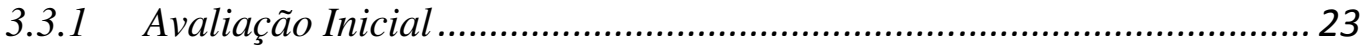

3.3.2 Avaliação da postura estática do pé (FPI-6)...................................... 23

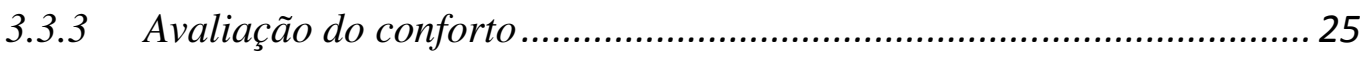

3.3.4 Avaliação da distribuição da pressão plantar ..................................... 27 
3.4 AVALIAÇÃO EM LABORATÓRIO - ETAPA II …........................................... 30

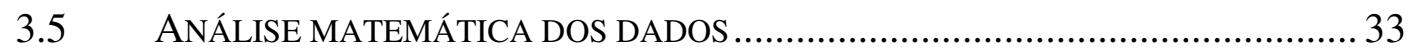

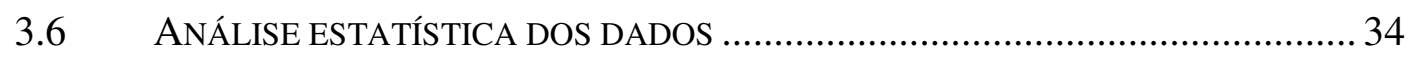

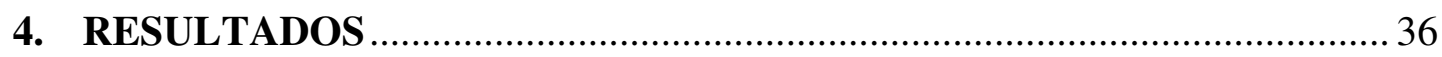

5. DISCUSSÃ

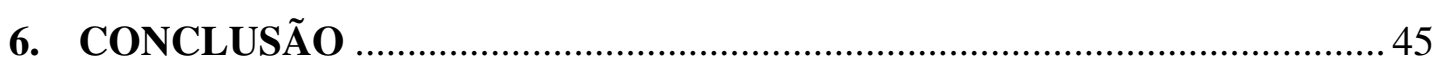

ANEXO 1 - TERMO DE CONSENTIMENTO LIVRE ESCLARECIDO....... 46

ANEXO 2 - APROVAÇÃO DO COMITÊ DE ÉTICA EM PESQUISA............ 48

ANEXO 3 - FICHA DE AVALIAÇÃO INICIAL .......................................... 49

ANEXO 4 - AVALIAÇÃO ANTROPOMÉTRICA PELO MÉTODO FPI ....... 50

ANEXO 5 - FICHA DE COLETA DOS DADOS DE CONFORTO .................. 51

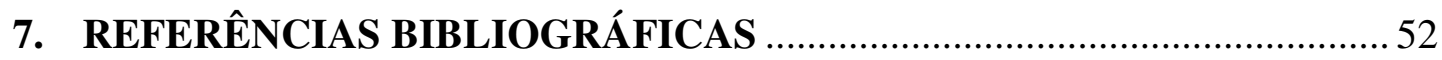

APÊNDICE A- ROTINA MATLAB PARA ANÁliSE DOS DADOS DA FORÇA REAÇÃO DO SOLO 


\section{LISTA DE SIGLAS}

$\begin{array}{ll}\text { ABNT } & \text { Associação Brasileira de Normas Técnicas } \\ \text { CORPORE } & \text { Associação de corredores paulistas reunidos } \\ \text { EVA } & \text { Etil vinil acetato } \\ \text { FPI-6 } & \text { Foot Posture Index } \\ \text { Fz }_{1} & \text { Primeiro pico vertical da força reação do solo } \\ \text { Fz }_{2} & \text { Segundo pico vertical da força reação do solo } \\ \text { LR 100 } & \text { Taxa de carga entre } 0 \text { e } 100 \% \text { do primeiro pico da força vertical } \\ \text { LR } 80 & \text { Taxa de carga entre } 20 \text { e } 80 \% \text { do primeiro pico da força vertical } \\ \mathrm{p} & \text { nível descritivo do teste } \\ \text { PC } & \text { Peso corporal } \\ \text { PU } & \text { Poliuretano } \\ \text { Tx } & \text { Taxa de propulsão }\end{array}$




\section{LISTA DE TABELAS}

Tabela 1 - Especificações dos calçados testados neste estudo.

Tabela 2 - Médias e desvio padrão das variáveis da força reação do solo vertical normalizadas pelo peso corporal (PC) dos quatro modelos de calçados analisados. 37

Tabela 3 - Médias e desvio padrão da área de contato, pico de pressão e integral da pressão para cada região da superfície plantar durante a corrida com os quatro modelos de calçados. 38 


\section{LISTA DE FIGURAS}

Figura 1 - Partes principais que compõem o calçado esportivo: [a] Cabedal, [b]

Palmilha, [c] Entressola, [d] Sola.

Figura 2 - Principais componentes da estrutura de um calçado de corrida predominantemente de EVA. 7

Figura 3 - A: maquina que simula o impacto do calcanhar no chão e determina o nível de amortecimento do calçado na região do retropé. B: maquina que avalia a resistência do calçado quanto às características de flexão na região do antepé. 8

Figura 4- Calçados comercialmente disponíveis que foram analisados e comparados:

A. Air, B. Gel, C. Adiprene, D. EVA $\neq$ densidades 22

Figura 5 - Postura utilizada na avaliação do Foot Posture Index, com o corredor em pé, com os pés em paralelo e braços alinhados ao corpo.

Figura 6 - Calçados utilizados nas coletas, mascarados com fita prateada e spray, etiquetas retiradas dos tênis e abrasão do solado. 26

Figura 7 - Corrida de 15 minutos para avaliação da percepção de conforto dos calçados pelos corredores em uma quadra plana da universidade de São Paulo. 27

Figura 8 - Sistema Pedar X (Novel, Alemanha) composto por: (A) Fitas velcro para fixação dos cabos; (B) palmilha capacitiva; (C) Unidade de Bluetooth; (D) Bateria e (E) Condicionador de sinais. 28 
Figura 9 - Esquema de coleta em campo: 40 metros de pista, avaliação da corrida a $12 \mathrm{~km} / \mathrm{h}( \pm 5 \%)$, monitorados por dois sensores fotoelétricos nos 20 metros intermediários usando os 4 modelos de calçados.

Figura 10 - Representação da divisão da superfície plantar em três áreas para a análise da distribuição da pressão plantar: retropé, mediopé e antepé.... 30

Figura 11 - Pista plana e regular de 10 metros no Laboratório de biomecânica, com a plataforma de força embutida no centro da pista, onde os corredores foram avaliados na segunda etapa do projeto.

Figura 12 - Representação gráfica das variáveis da força reação do solo vertical, onde $(\mathrm{Fz} 1) 1^{\circ}$ pico vertical da força reação do solo, $(\mathrm{Fz} 2) 2^{\circ}$ pico vertical da força reação do solo, (LR 80) taxa de carga entre 20 e $80 \%$ do $1^{\circ}$ pico vertical da força reação do solo, (LR 100) taxa de carga entre 0 e $100 \%$ do $1^{\circ}$ pico vertical da força reação do solo e (Txp) taxa de propulsão... 33

Figura 13 - Valores médios e desvio padrão obtidos da escala analógica da percepção de conforto dos calçados Air, Gel, Adiprene e EVA. *representa diferença estatística entre os calçados sinalizados. 36 


\section{RESUMO}

DINATO, RC. -Variáveis biomecânicas relacionadas ao impacto e percepção de conforto em calçados de corrida com diferentes tecnologias de amortecimento [dissertação]. São Paulo: Faculdade de Medicina, Universidade de São Paulo; 2013.

Este trabalho teve como objetivo investigar as relações entre a percepção de amortecimento, conforto e as variáveis biomecânicas relacionadas ao impacto (pressão plantar e força reação do solo) durante a corrida comquatro diferentes tecnologias de amortecimento de calçados esportivos. Vinte e dois corredores recreacionais do sexo masculino (18 a 45 anos) correram $(12 \mathrm{~km} / \mathrm{h})$ com 4 calçados de corridacom diferentes sistemas de amortecimento: Gel, Air, Adiprene e EVA (Etil Vinil Acetato) comdiferentes densidades. Nove itens relacionados a percepção do conforto, cinco variáveis da força de reação do solo e nove da pressão plantar foram avaliadas durante a corrida. Cincovariáveis biomecânicas relacionadas à força reação do solo produzida durante a corrida foram mensuradas por meio de uma plataforma de força em ambiente de laboratório e nove variáveis relacionadas à pressão plantar foram adquiridas pelo sistema PedarX de palmilhas em uma pista de corrida. As 14variáveis biomecânicas e os nove itensde conforto foram comparados entre os calçados por meio de ANOVAs para medidas repetidas. As relações entre as variáveis da força e da pressão plantar e entre conforto geral e as variáveis biomecânicas foram investigadas por meio docoeficiente de correlação de Pearson. Análises de regressão stepwise backward foram realizadas para predizer o conforto geral e as percepções do amortecimento na região do retropé e antepé de cada calçado. A análise de correlação feita entre o conforto geral e as variáveis biomecânicas para cada um dos4 modelos de calçados apresentou relações entre fracas e moderadas, embora não significativas. A análise de regressão revelou somente para o calçado Adiprene que 56\% do conforto geral percebido pelo usuário pode ser explicado pelas variáveis taxa de propulsão e integral da pressão no antepé $(\mathrm{p}=0,015)$ e que $33 \%$ da percepção de amortecimento no antepé pode ser explicado pelas variáveis segundo pico de força e taxa de propulsão $(\mathrm{p}=0,016)$. Assim, de maneira geral, não se pode predizer o conforto geral e a percepção de amortecimento dos calçados estudados por meio do impacto e da pressão plantar recebidos, já quesomente uma entre quatro tecnologias estudadas apresentou este comportamento de predição.

Descritores: Corrida, Sapatos, Biomecânica, Pressão, Cinética, Amortecimento, Tecnologia de produtos, Masculino, Confort. 


\section{SUMMARY}

DINATO, RC. -Biomechanical impact-related variables and perception of comfort in running shoes with different cushioning technologies [dissertation].São Paulo: School of Medicine, University of Sao Paulo; 2013.

This study aimed to investigate the relationship between the perception of comfort and impact-related biomechanical parameters (plantar pressure and ground reaction force) during running with four different types of cushioning technology in running shoes.Twenty-two men, recreational runners (18 to 45 years) ran $12 \mathrm{~km} / \mathrm{hwith}$ running footwear with four different cushioning systems: Gel, Air, Adiprene e EVA (Ethyl Vinyl Acetate) com various densities. Outcome measures included nine items related to perception of comfort,five variables of ground reaction force and nine of plantar pressure that were evaluated during running. Five biomechanical variables related to ground reaction force were acquired with an AMTI force plate in the laboratory environment. Nine variables related to plantar pressure were acquired by the PedarX system instrumented insoles on a running track.The 14 biomechanical variables and the nine items of comfort were compared amongfootwears using repeated measure ANOVAs. Pearson correlation coefficients were calculated to investigate the relationship between the perceptions of comfort and the biomechanical variables for all the footwear. Step-wise regression analyses were employed to determine which group of the biomechanical variables could best predict general footwear comfortand perception of cushioning in the rearfoot and forefoot region of each evaluated footwear.Correlation analysis made between the general comfort and biomechanical variables for the four types of shoesshowed between low and moderate correlation coefficients,although not significant. Regression analysis revealed that $56 \%$ of the perceived general comfort can be explained by the variables push-off rate and pressure integral over the forefoot $(p=0.015)$ and that $33 \%$ of the cushioning perception over the forefoot can be explained by second peak force and push-off rate $(p=0.016)$. Thus, in general, one cannot predict the overall comfort and cushioning perception of a running shoe studied through impact and plantar pressure received, since only one of the four technologies studied showed this behavior prediction.

Descriptors: Running, Shoes, Biomechanics, Pressure, Kinetics, Cushioning, Products Technology, Male, Confort. 


\section{INTRODUÇÃO}

\subsection{Contextualização do problema de pesquisa}

O propósito inicial do calçado esportivo é proteger o indivíduo de possíveis lesões e cargas repetitivas no sistema musculoesquelético, proteger a superfície plantar de pedras, vidros e variações de temperatura(Squadrone e Gallozzi, 2009), controlar o movimento do pé e tornozelo (Mcnair e Marshall, 1994) e contribuir com o desempenho esportivo.

As características dos materiais e a construção da entressola de um calçado esportivo podem determinar sua absorção de choque e as propriedades de atenuação de impacto (Frey, 1997).

A natureza das adaptações do sistema musculoesquelético à sobrecarga repetitiva promovida pela corrida são incertas e ainda duvidosas, especialmente os mecanismos pelos quais estas adaptações ocorrem em função do uso do calçado esportivo, de um determinado piso ou ainda da duração do treino (Hardin et al., 2004).

O sistema musculoesquelético necessita de certo tempo para se adaptar ao uso de um novo calçado ou para se recuperar do estresse sofrido pelas sobrecargas repetitivas promovidas pelo treinamento da corrida. A negligência do corredor em relação a este período de recuperação pode acarretar na ocorrência de lesões musculoesqueléticas, como a periostite na tíbia e condromalácia patelar (Hreljac, 
2004), além de outras lesões bem recorrentes em corredores, como a fasciite plantar e síndrome da banda iliotibial (Taunton et al., 2002).

Adicionalmente, as exposições prolongadas a suscetíveis forças de impacto e a pronação do pé, também têm sido estudadas extensivamente em corredores e apontadas como uma das maiores razões para o desenvolvimento de lesões (Milner $e t$ al., 2006; Ryan et al., 2011). Desta forma, uma das funções que o calçado de corrida poderia proporcionar seria o adequado alinhamento do complexo tornozelo pé, reduzindo a pronação ou supinação excessivas. Clarke et al. (1983a) encontraram maior pronação de retropé em calçados esportivos que utilizavam materiais mais macios na entressola e descreveram que a altura do calcanhar no calçado não tem efeito na magnitude da pronação. Outros autores encontraram uma maior pronação e maior velocidade de pronação em calçados com entressola mais duras (Nigget al., 1987a). Estes autores sugeriram que fosse utilizado um material mais macio na porção lateral da entressola e um material mais duro na área medial, com o intuito de limitar esta pronação do pé e maiores velocidades.

Outro estudo mais recente realizado por Cheung e $\mathrm{Ng}$ (2008) revelou que calçados com características de pisada neutra com apenas um nível de rigidez na entressola na região calcanhar, não foi capaz de controlar o excessivo movimento do retropé em corredoras recreacionais com ângulo de pronação postural maior que $6^{\circ}$. Entretanto, quando essas corredoras utilizaram um calçado com controle de movimento do retropé, contendo dois níveis de rigidez na entressola, sendo a região medial do calcanhar mais dura que a lateral, não houve mudanças nas magnitudes e nas distribuições das forças plantares. Os autores concluem que a seleção do calçado 
para corredores recreacionais com mais de $6^{\circ}$ de pronação é importante na prevenção de lesões.

Contrariando os estudos anteriores, Nigg (2001) propôs um novo paradigma a respeito das forças de impacto e pronação do pé, através de uma análise crítica da literatura dos últimos 25 anos a partir da data de publicação do referido artigo. O autor propõe que as forças de impacto são sinais de entrada que promovem a ativação muscular antecipadamente ao próximo contato com o solo, para minimizar a vibração dos tecidos moles, reduzindo assim as cargas articulares. Esta contração muscular antecipada pode reduzir a fadiga, melhorar o conforto e a performance, desta forma, as evidências experimentais que sugerem o conceito de alinhamento do complexo tornozelo-pé por meio de um calçado esportivo deveria ser reconsiderado. No entanto, futuros estudos experimentais e teóricos são necessários para comprovar este paradigma proposto.

A interação dos materiais da entressola e o modelo dos calçados dificulta a previsão de como o corredor pode reagir a um calçado específico (Frederick, 1986). Isto também pode explicar por que tem sido difícil estabelecer conexões diretas entre o calçado, as forças de impacto e as lesões.

Esta alta e persistente prevalência de lesões em corredores ao longo das três últimas décadas podem ter ocorrido devido ao excesso e a diversificação do treinamento, a massificação de acessórios indicados para a prática da modalidade e ao uso aleatório de diversos calçados esportivos, porém, nenhuma destas evidências possui embasamento científico (Hohmann e Imhoff, 2003).

Nos últimos 30 anos, a popularização e a prática da corrida aumentaram consideravelmente no Brasil e no mundo (Feehery, 1986; Novacheck, 1998; De Wit 
et al., 2000; Nigg, 2001; Tillman et al., 2002), ocasionando um aumento acentuado no número de praticantes, principalmente os considerados corredores recreacionais, já queseu baixo custo associado aos possíveis benefícios à saúde atraem homens e mulheres de todas as idades.

Este aumento do número de praticantes da modalidade associado aos altos índices de lesão (Macera, 1992; Van Mechelen, 1992; Taunton et al., 2002) foram fatores que estimularam a procura da população por calçados mais confortáveis e supostamente protetores, ou ainda que propiciassem a melhora da performance nesta modalidade. Divert et al .(2008) ao analisar o efeito da massa do calçado esportivo no consumo de oxigênio durante a corrida, concluiu que o aumento do custo metabólico foi influenciado pelo aumento da massa do calçado e não devido a propriedades estabilizadoras ou as características de amortecimento (Martin, 1985). Outro estudo demonstrou que o uso do calçado com material visco elástico na região do retropé reduziu em $2 \%$ o consumo de oxigênio de corredores em relação ao uso do calçado com material elástico em sua entressola (Nigg et al., 2003a). Frederick (1984) demonstrou que calçado esportivo com entressola mais macia geralmente esta associado a um consumo mais baixo de oxigênio.

O efeito do calçado na economia da corrida ou até mesmo uma relação direta com a incidência de lesão, ainda permanece uma questão difícil de mensurar. Uma explicação de como ocorre a interação entre os materiais utilizados nos calçados e o corredor, gerou um maior interesse científico para o desenvolvimento de novos produtos e tecnologias para reduzir potenciais fatores de risco de lesões ou aumentar a performance durante a prática desta modalidade. Iniciou-se, então, a construção 
decalçados esportivos cada vez mais específicosà pratica da corrida, favorecendo o desenvolvimento de novas tecnologias e materiais (James et al., 1978).

\subsection{Estrutura e construção do calçado esportivo}

A estrutura de um calçado esportivopode ser descritade maneira geralem: parte superior - o cabedal, e parte inferior- o solado. Cada uma destaspartes se subdivide em outras partes com características e funções bem definidas, conforme ilustrado na Figura 1.

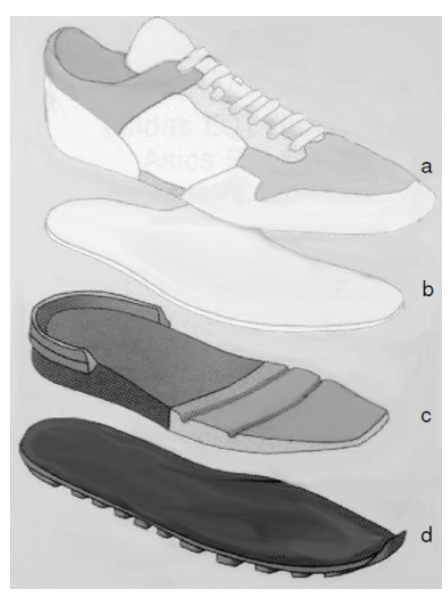

Figura 1 - Partes principais que compõem o calçado esportivo: [a] Cabedal, [b] Palmilha, [c] Entressola, [d] Sola.

O cabedal tem a função de proteger os pés e melhorar a percepção de conforto do calçado, podendo variar no tamanho, na forma e nos materiais que o constituem. Normalmente, é constituído de várias peças e reforços, usados para dar mais firmeza e proteção à parte superior do pé. Entre os elementos de reforço está o contraforte. O contraforte é um reforço colocado na região do calcanhar, destinado a dar forma a esta parte docalçado e manter o calcanhar firme dentro do sapato, sendo 
um elemento importante no calce e no conforto (Andrade e Correa, 2001). A palmilha é fabricada com o mesmo Etil Vinil Acetato (EVA) empregado na entressola, aumentando o conforto, ou com a função adicional de conferir maior sustentação ao arco longitudinal medial dos pés. A entressola é uma camada intermediária colocada entre a palmilha e a sola, com função estética e de amortecimento e a sola é a parte em contato direto com o solo, e o seu perfil determina sua propriedade, durabilidade, flexibilidade, resistência à umidade, leveza, uniformidade, resistência ao deslizamento, entre outros fatores (Andrade e Correa, 2001).

Até a década de 80, as entressolas dos calçados de corrida eram predominantemente feitas de EVA, enquanto que para os calçados casuais as entressolas eram constituídas principalmente de Poliuretano (PU) e acreditava-se que os mecanismos de amortecimento destes materiais seriam suficientes para atenuar as forças impostas asestruturas musculoesqueléticas durante o toque do calcanhar com o solo durante a locomoção. A escolha pela espuma de EVA para construção dos calçados esportivos em oposição à espuma de PU se baseia na característica de ser extremamente leve e com uma boa durabilidade, proporcionando um suposto menor gasto energético, embora não haja ainda comprovação científica (Brueckner et al., 2011). Atletas de elite costumam utilizar calçados esportivos com até $100 \mathrm{~g}$ de massa durante uma prova e calçados mais pesados, cerca de $300 \mathrm{~g}$ durante os treinos, em virtude de sua maior durabilidade. O modelo padrão de calçado esportivo com entressola de EVA pode ser visto na Figura 2. 


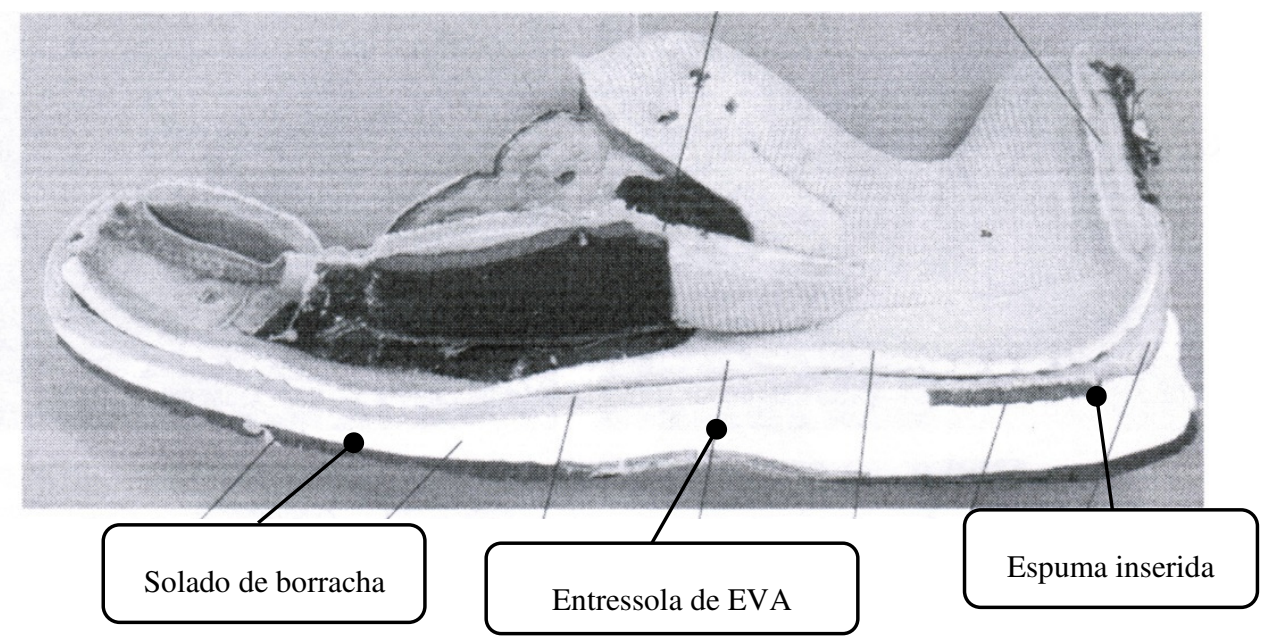

Figura 2 - Principais componentes da estrutura de um calçado de corrida predominantemente de EVA.

Até a década de 80, as pesquisas e consequentemente o foco no desenvolvimento do calçado esportivo tinham uma abordagem relacionada aos resultados de testes mecânicos de materiais, não envolvendo reações fisiológicas e biomecânicas ou feedback sensorial dos usuários dos calçados. Isto resultou em interpretações parciais que foramutilizadas na construção dos calçados (Nigg e Morlock, 1987). Os testes mecânicos são feitos através de máquinas de ensaio que simulam as cargas impostas aocorpo humano durante a corrida (Figura 3). Usa-se para testar a capacidade de amortecimento destes materiais, sistemas hidráulicos que fazem sucessivas compressões na parte interna do calçado na região do retropé ou teste mecânico de impacto que consiste em uma massa móvel de peso conhecido instrumentada com um acelerômetro que se desloca de uma altura conhecida até o calçado, onde a desaceleração desta massa promovida pelos componentes do calçado é medida e atribuído então valores para aatenuação do impacto. Estas condições tentam simular o impacto do calcanhar no solo durante a corrida (Hennig et al., 1996; Hennig e Milani, 2000a). 

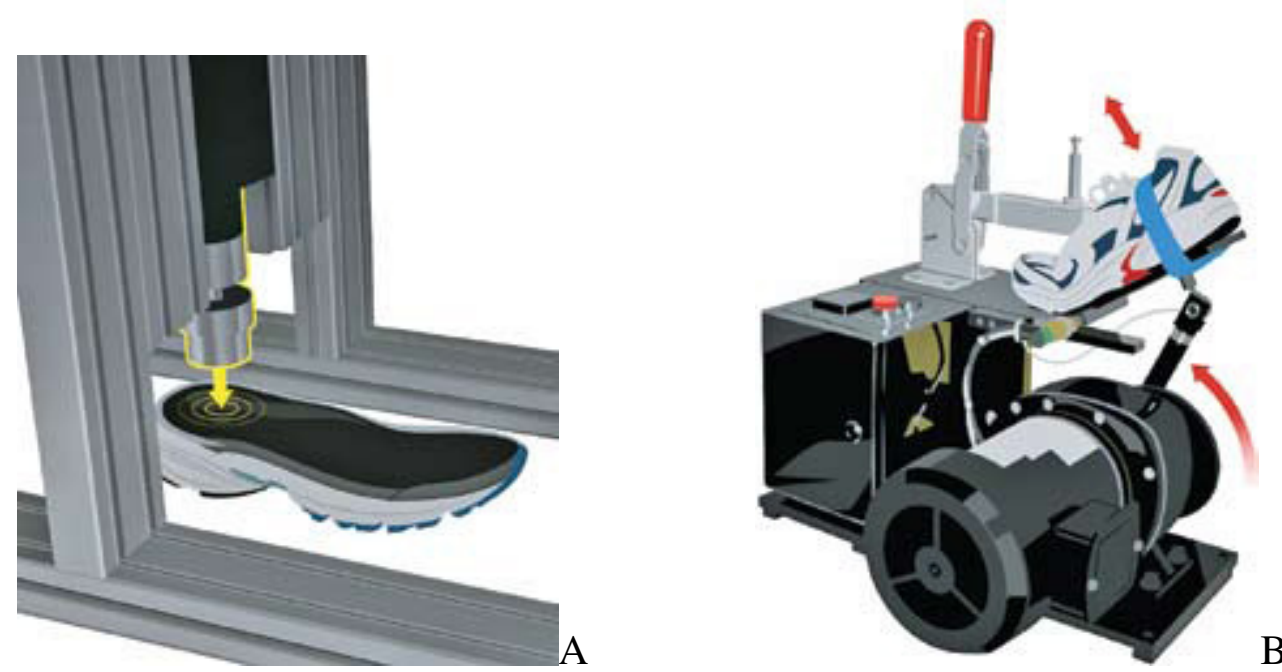

Figura 3 - A: maquina que simula o impacto do calcanhar no chão e determina o nível de amortecimento do calçado na região do retropé. B: maquina que avalia a resistência do calçado quanto às características de flexão na região do antepé.

\subsection{Avaliações biomecânicas de calçados esportivos}

A partir da década de 80 , surgiram novas tecnologias para absorção de impacto nos calçados esportivos, sendo a Nike uma das precursoras no desenvolvimento de novos materiais e estruturas, através da tecnologia Air, que consiste em câmaras de ar inseridas na entressola dos calçados(Cavanagh e Lafortune, 1980).

Com a finalidade de melhorar a compreensão de como o corpo humano interage com o calçado e avançar com a tecnologia das construções de calçados esportivos, iniciou-se avaliações mais elaboradas das forças que estão agindo no corpo e não somente no calçado. O raciocínio para tal questão era que durante a corrida as forças verticais de reação do solo geradas são 2,5 vezes maiores que o 
peso corporal (Cavanagh e Lafortune, 1980), o que resulta em sobrecarga em toda a cadeia cinética inferior.

Ao longodos anos, os estudos foram se aperfeiçoando e durante mais de três décadas estudos baseados na força reação do solo foram usados como base para compreender os mecanismos de interação corpo-calçado e qual a contribuiçãode fatores externos, como: superfície, estilo de corrida e tipos de calçados poderiam aumentar ou diminuir esta sobrecarga na cadeia cinética inferior (Cavanagh e Lafortune, 1980; Clarke et al., 1983b; Lieberman et al., 2010).

Com esta preocupação Clarke et al. (1983b) e Hreljac (1998) avaliaram calçados com entressola de EVA (construção comum dos calçados na década de 80) com diferentes durezas, e concluíram que cadaparticipante demonstrou preferência por um específico modelo de calçado testado, sendo que o tempo para se atingir o pico da força vertical foi maior no calçado macio, no entanto, não foram observadas diferenças para as magnitudes destas forças.

Segundo Hreljac (1998) e Radin et al.(1991), o impacto do pé com o solo causa forças que são transmitidas as extremidades inferiores com altas taxas de carga, "loading rate", sendo maiores em corredores com histórico de lesão comparados a corredores que não apresentaram lesão.

Baseando-se nestas premissas, os estudos mais recentes envolvendo a população corredora foram mais direcionados a investigar as relações dos impactos promovidos pela corrida e o histórico de lesão. Milner et al.(2006) observaram que corredoras acima de 40 anos com fratura por estresse na Tíbia apresentavam maiores taxas de cargas sobre as extremidades inferiores. Segundo esses autores, estes resultados serviram para melhorar o desempenho com a utilização de um calçado 
com maior amortecimento (Lilley et al., 2011). Bredeweg et al. (2012) demonstraram, que corredores novatos com lesões relacionadas a corrida apresentaram maiores taxas de carga e menores tempos de contato em relação a corredores novatos sem histórico de lesão, indicando que altas taxas de carga nesta população pode ser um fator de risco para lesões relacionadas a corrida. Para Lieberman et al. (2010), outra variável de interesse na corrida é o impacto transitório ("Impact Transient"), que é definido entre o toque do calcanhar no solo e o pico de força vertical, que ocorre nos primeiros $50 \mathrm{~ms}$ da fase de apoio.

Esta variável associada a corrida de retropé são forças repentinas com altas taxas e magnitudes de carga transmitidas aos membros inferiores e atualmente, vem sendo associadas a ocorrência de lesão em corredores, tais como fratura por estresse na tíbia e fasciite plantar (Van Gent et al., 2007; Crowell e Davis, 2011)

Bredeweg et al. (2012), Cavanagh e Lafortune (1980), Clarke et al.(1983), Divert et al.(2005) e Lieberman et al.(2010) adotaram a força reação do solo como um parâmetro para inferir o impacto durante a corrida em função do calçado, piso ou técnica de corrida.Outra variável que vem sendo usada como outro parâmetro para inferir impacto e quantificar o avanço tecnológico do calçado é apressão plantar. Hennig e Milani (2000), Dixon (2008), Verdejo e Mills (2004) e Nigg et al. (2003b) recomendam o uso da avaliação da pressão plantar in-shoe para investigar o risco de lesão por sobrecarga na corrida. Dixon (2008) recomenda fortemente o uso da mensuração da pressão plantar in-shoe como um potencial método para prescrever o calçado apropriado, além de ser suficientemente sensível e eficiente para distinguir diferenças das características de amortecimento dos calçados esportivos. 
Segundo Hennig e Milani (2000), por meio do pico de pressãoe da carga relativa, é possível compreendero comportamento mecânico do pé durante a corrida, possibilitando ainda determinar em que momento o calçado esportivo perde suacapacidade de absorção de impacto em função de seu uso. Portanto, as medidas de pressão plantar adicionam informações para melhor compreensão da interação do corpo com o calçado e solo, além do que a força reação do solo pode fornecer.

Wegener et al. (2008) demonstraram que dependendo do sistema de amortecimento (Gel e HidroFlow) constituinte do calçado é possível reduzir picos de pressão em corredores com arco longitudinal plantar alto. Já Burns et al. (2005) sugerem que a integral da pressão é a melhor variável para representar as cargas em corredores com pé cavo.

Clinghan et al. (2008) também por meio da distribuição da pressão plantar, concluem que calçados cujos preços variam dos baratos aos caros, não diferem quanto a sua capacidade de amortecimento.

Wiegerink et al. (2009) demonstraram significantes diferenças de pico de pressão, força máxima e área de contato entre dois calçados esportivos com o mesmo sistema de amortecimento, mas localizadosem regiões diferentes do pé: um calçado utilizado para treino com sistema de amortecimento no retropé e antepé e um calçado para competição com sistema de amortecimento somente no retropé. Os resultados deste estudo indicaram que calçados com sistema de amortecimento em regiões diferentes do pé podem alterar as cargas plantares, sendo importante a escolha de um calçado de corrida para treino ou competição, uma vez que, estas características determinam os locais onde estão inseridos os sistemas de amortecimento. 
Verdejo e Mills (2004) investigaram quando começa a ocorrer a degradação na capacidade de amortecimento na entressola dos calçados esportivos com diferentes densidades da espuma de EVA, por meio da mensuração do pico de pressão. Os autores concluíram que o pico de pressão aumentou em 100\% após500 km de corrida eatravés de uma análise microscópica, foi possível verificar danos na estrutura do EVA após $750 \mathrm{~km}$ de uso. A fadiga da espuma de EVA diminuiu as propriedades de amortecimento ao toque do calcanhar no solo e esta diminuição pode ser uma das possíveis causas de lesão em corredores.

\subsection{Avaliação do conforto de calçados esportivos e sua relação com a biomecânica}

A percepção de atenuação de cargas tem sido foco de investigação de alguns estudos que buscaram associá-la com as variáveis biomecânicas relacionadas ao impacto (força reação do solo e pressão plantar) (Milani et al., 1997; Mündermann et al., 2001; Wegener et al., 2008).

Milani et al. (1997) encontraram altas correlações entre variáveis biomecânicas e percepção de amortecimento ao analisarem oito calçados de corrida com diferenças apenas na rigidez da entressola. Os resultados mostraram que há uma tendência a menores forças de impacto vertical em calçados mais duros, indicando que os atletas adaptam seu estilo de corrida para evitar altos impactos na região do calcanhar e que apesar da sensibilidade em perceber diferentes amortecimentos, os corredores não são capazes de identificar um calçado que protje o corpo de altos impactos. 
Hennig et al. (1996) analisaram três modelos de calçados esportivos com diferentes durezas de entressola de EVA (macio, médio e duro) e concluíram que as variáveis da força reação do solo (primeiro pico vertical e taxa máxima da força) e da pressão plantar (pico de pressão no calcanhar) demonstraram altas correlações com a classificação subjetiva de amortecimento. Também concluíramque, dependendo da rigidez da entressola, as forças de impacto, inferidas pelas variáveis da força reação do solo e pressão plantar, podem ser alteradas. Os resultados deste estudo indicaram ainda, que as medidas da pressão plantar podem ser importantes indicadores para representar a percepção de amortecimento dos usuários.

Baseado nosresultados dos estudos de Hennig et al. (1996) e Milani et al. (1997), quanto melhor a percepção de amortecimento, maiores os impactos mensurados. Essesautores sugerem que o nosso sistema perceptivo-sensorial consegue distinguir impactos de diferentes frequências e magnitudes, em função das características de construção dos calçados esportivos, particularmente da rigidez da entressola, e realizam ajustes cinemáticos na sua técnica de corrida para reduzir esses impactos sobre estruturas anatômicas do pé.

Chen e Nigg (1994) demonstraram que a distribuição da pressão entre a superfície plantar do pé e o calçado, poderia detectar as mudanças na percepção de conforto no calçado, mas que os resultados durante a corrida sugerem que as medidas da pressão plantar pode não ser sensível o suficiente para detectar mudanças no conforto. Portanto, se as diferenças de pressão plantarnão forem grandes o suficiente, o conforto só poderia ser predito durante o andar, por meio destas variáveis, mas não durante o correr. Hong et al.(2005) utilizaram a força reação do solo e a pressão plantar para avaliar o confortocom a introdução de palmilhas em calçados com 
diferentes alturas no calcanhar durante a marcha. Os resultados indicaram que o pico de pressão e o primeiro pico vertical da força reação do solo são variáveis que podem ser usadas para predizer o conforto. Os autores observaram também, que o uso de palmilha altera a biomecânica da marcha e melhora a sensação de conforto em calçados com calcanhar elevado.

Apoiando os resultados de Chen e Nigg (1994), Wegener et al. (2008) demonstraram que não houve relação da percepção de conforto com as variáveis de pressão plantar durante a corrida em calçados com diferentes sistemas de amortecimento ( $\mathrm{Gel}$, HydroFlow). Os resultados do estudo mostraram que não houve relação entre o conforto percebido e as variáveis de pressão plantar em qualquer região do pé e que a percepção de conforto não é um bom indicador para demonstrar a redução de pressão plantar em calçados esportivos.

Miller et al. (2000) associou a percepção de conforto comas características de flexibilidade, rigidez da entressola e dimensões internas de calçados esportivos e o alinhamento do pé durante a marcha e a corrida. Os autores encontraram fortes correlações entre as percepções de conforto e as características do calçado esportivo tantodurante o andar como durante ocorrer. Também foram observadas que as classificações das percepções de conforto mudaram dependendo da atividade que estava sendo realizada: correr ou andar. A percepção de conforto diminuiu da marcha em relação a corrida, reforçando o fato que o conforto de um dado calçado depende não apenas de características individuais, mas também da atividade que esta sendo realizada.

No Brasil, criaram-se normas especificas para avaliação do conforto em calçados femininos, masculinos e infantis. A norma técnica Brasileira para avaliação 
de conforto do calçado (ABNT 14834:2011) foi elaborada por uma comissão formada por representantes dos produtores, consumidores, universidades e laboratórios. Esta norma estabelece os métodos de ensaios e os requisitos para estabelecer o índice de conforto dos calçados. Seis ensaios são sugeridos para classificar o conforto, são eles:

- $\quad$ ABNT NBR 14835: estabelece o método para determinação da massa do calçado. Calçados masculinos com massa acima de $580 \mathrm{~g}$ são considerados muito desconfortáveis e abaixo de $280 \mathrm{~g}$ muito confortáveis.

- ABNT NBR 14836: estabelece o método para determinação dos picos de pressão plantar na região do calcâneo e na região das cabeças dos metatarsos durante a marcha. Níveis de pico de pressão abaixo de $240 \mathrm{kPa}$ é considerado confortável e acima de $320 \mathrm{kPa}$ é considerado desconfortável.

- ABNT NBR 14837: estabelece o método para determinação da temperatura interna do calçado com duração de 30 minutos de marcha em esteira. Temperaturas abaixo de $3,5^{\circ} \mathrm{C}$ são consideradas confortáveis e acima de $5,5{ }^{\circ} \mathrm{C}$, desconfortáveis.

- ABNT NBR 14838: estabelece o método para determinação do índice de amortecimento do calçado durante a marcha, por meio do uso de plataforma de força. Índices maiores que 50\% sãoconsideradosconfortáveise menores que 35\%, desconfortáveis.

- ABNT NBR 14839: estabelece o método para determinação do índice de pronação do calçado durante a marcha. Índices de pronação entre 0 e 3 graus são considerados confortáveis e maiores que 6 graus ou negativo, desconfortáveis. 
- ABNT NBR 14840: estabelece o método para determinação dos níveis de percepção do calce e dos níveis de conforto da percepção do calce correspondente à avaliação das marcas e/ou lesões, durante a marcha em esteira com duração de 30 minutos.

A tentativa de definir o conforto dos calçados produzidos no Brasil através de avaliações biomecânicas pela Associação Brasileira de Normas Técnicas é valida, porém os critérios adotados para classificar o conforto são inconsistentes com a literatura. Inicialmente, todos os testes para se determinar o conforto dos calçados são realizados na marcha. Já se sabe que há diferenças na percepção de conforto entre o andar e correr (Miller et al.,2000). Desta forma, torna-se inviável a utilização desta metodologia neste estudo para se definir o conforto do calçado esportivo durante a corrida. Outro fator bastante controverso é a classificação do conforto através dos valores obtidos das análises biomecânicas, uma vez que, ainda não esta claro como o conforto dos calçados pode se relacionar com estas variáveis.

A quantificação do conforto, por ser uma questão subjetiva, ainda permanece sem um padrão ouro de avaliação e ainda são inconclusivos os resultados da relação entre o conforto percebido ou a percepção de amortecimento que o calçado oferece e as medidas biomecânicas que denotam impacto.

Considerando que indicadores de impacto mensurados por meio de métodos biomecânicos auxiliariam na prescrição de calçados esportivos (Dixon, 2008), seria muito importante investigar se o usuário é capaz de perceber se o calçado atenua impacto da mesma forma que a avaliação biomecânica poderia concluir e como seria sua percepção de conforto, já que esse fator está intimamente relacionado com a 
percepção que o corredor tem das cargas em seu corpo durante sua prática esportiva. Se isso fosse confirmado, o corredor também poderia se beneficiar de tal percepção para escolher seu calçado.

Há que se ressaltar que os estudos anteriores que fizeram a relação entre conforto e pressão plantar ou força reação do solo (Hennig et al., 1996; Milani et al., 1997) investigaram apenas o quanto diferenças na rigidez da entressola de EVA altera a percepção do usuário e as variáveis biomecânicas, não incluindo ou especificando as tecnologias de amortecimento dos calçados estudados. Algumas tecnologias tais como air, gel, wave, dmx dentre outras foram introduzidos no solado dos calçados de corrida após os anos 90 com a intenção de incrementar a atenuação do impacto. Acredita-se que taistecnologiaspoderiam alterar as variáveis biomecânicas relacionadas ao impacto, a percepção que o corredor tem da capacidade de amortecimento, bem como a percepção de conforto geral que o usuário tem desse calçado. Dessa forma, seria fundamental uma investigação biomecânica que busque potenciais relações entre a percepção de atenuação de impacto e de conforto e a redução de cargas em calçados de corrida com construções de solado que incluíssem essas novas tecnologias de amortecimento. 
2 OBJETIVOS

\subsection{Objetivo Geral}

O objetivo do estudo foi investigar as relações entre a percepção de amortecimentoe conforto geral do calçadoe variáveis biomecânicas relacionadas ao impacto durante a corrida em calçados esportivos comquatro diferentes tecnologias de amortecimento: Gel, Air, Adiprene e EVA com diferentes densidades.

\section{$2.2 \quad$ Teses}

i. O calçado com tecnologia predominantemente de EVA apresentaria menores taxas de carga em relação aos outros calçados, porém pior conforto e percepção de amortecimento, tal como foi observado por Hennig et al.(1996) e Milaniet al. (1997).

ii. Os outros calçados (Air, Gel e Adiprene) apresentariam menores taxas de carga, melhor conforto e percepção de amortecimento, já que materiais agregados a entressola teriam potencial de incrementar a atenuação de cargas.

iii. Haverá correlação entre as variáveis biomecânicas associadas ao impacto em retropé e antepé e o conforto nos calçados com adição de novas tecnologias de amortecimento. 


\section{3 CASUÍSTICA E MÉTODOS}

\subsection{Casuística}

Fizeram parte deste estudo 22 corredores recreacionais do sexo masculino, com idade de 39,4 $\pm 6,6$ anos, $76,1 \pm 9,2 \mathrm{~kg}, 1,73 \pm 0,04 \mathrm{~m}$, e índice de massacorporal de $23,4 \pm 5,9 \mathrm{~kg} / \mathrm{m}^{2}$, com tempo médio de corrida em provas de 10 $\mathrm{km}$ de 48,6 $\pm 8,2$ min. O tempomédio de prática de corrida foi $5,2 \pm 3,4$ anos e volume médio de treino semanal de 35,9 $\pm 8,2 \mathrm{~km}$. Todos os participantes tiveram conhecimento dos procedimentos do estudo por meio de um termo de consentimento livre e esclarecido (ANEXO 1), aprovado pelo Comitê de Ética em pesquisa da Faculdade de Medicina da Universidade de São Paulo (protocolo 329/11) (ANEXO 2).

Os corredores que se voluntariaram a participar do estudo foram recrutados a partir de uma divulgação em mídia eletrônica através da associação de corredores Paulistas Reunidos (CORPORE).

Os critérios de elegibilidade para participar do estudo foram: idade entre $18 \mathrm{e}$ 45 anos, experiência em corrida de no mínimo um ano, volume de treino de no mínimo $20 \mathrm{~km}$ semanais, tamanho de calce 40 (tamanho dos calçados disponíveis para avaliação), técnica de corrida com apoio de retropé, não terem sofrido lesão musculoesquelética nos últimos seis meses, sem dismetria maior que $1 \mathrm{~cm}$ (distância umbigo - maléolo lateral). 
Os critérios de exclusão foram: alguma malformação congênita, deformidades ortopédicas adquiridas, calosidade acentuada na superfície plantar, sequelas de cirurgias anteriores nos membros inferiores, diminuição ou perda de sensibilidade superficial ou profunda na superfície plantar causadas por diabetes ou hanseníase, pronação ou supinação excessiva do complexo tornozelo pé classificados pelo Foot Posture Índex (Redmond et al., 2006), abandono, desistência e traumatismos durante as medições.

Foram selecionados inicialmente 28 corredores para participar do estudo, entretanto, devido a perda de dadose por desistência quando convocados para a segunda etapa do estudo, foram excluídos 6 corredores, totalizando ao final 22 corredores.

Foi realizado um calculo amostral no software GPower v.3.0.10, assumindose um erro tipo I $(\alpha)$ de $5 \%$, poder do teste de $80 \%$, com tamanho de efeito moderado ( $\mathrm{f}=0,25$ ), um design estatístico de teste $\mathrm{F}$ para medidas repetidas (efeito within), obtendo-se um $n$ de 17 corredores. Portanto o número de 22 corredores avaliados superou a quantidade inicial necessária para um poder estatístico de $80 \%$.

\subsection{Calçados avaliados}

Foram avaliados quatro calçados esportivos de tamanho 40 (Figura 4, tabela 1). Este calce foi escolhido por ser um número comum de usomasculino e assim permitir uma maiorquantidade de corredores que pudessem participar do estudo. Os calçados comprados eram de marcas conhecidas no mercado e de uso comum aos corredores. Todos os calçados foram adquiridos pelo laboratório, sem 
qualquerconflito de interesse com os fabricantes. A faixa de preço variou entre $R \$$ 200,00 e R \$ 300,00com o intuito de aproximar as características de construção dos calçados. As especificações técnicas de cada modelo podem ser vista na tabela 1 . Foram eles:

- Calçado com tecnologia Air: tênis amortecido com sustentação leve, superfície com malha aerada com sobreposições de tecido. Possui elementos externos de reflexão para permitir visibilidade em condições de luz baixa. Cabedal confeccionado em Mesh (tipo de malha de poliéster com tramas abertas) com Tecnologia FlyWire (promove estabilidade e controle dos pés, além de tornar a parte superior mais leve). Forro têxtil interno com reforço acolchoado no calcanhar em Meshque propicia maior absorção na transpiração local com proteção e conforto. Palmilha de EVA removível com Sistema FitSole (promove um encaixe com suporte ao arco do pé.

- Calçado com tecnologia GEL: Cabedal confeccionado em Mesh com reforço em tela de PU, sem costuras. Solado em borracha de alta resistência à abrasão que oferece maior durabilidade à parte traseira da sola. Lingueta fina e acolchoada em Ecsaine (tecido com toque suave). Palmilha anatômica em EVA removível que facilita a higienização. Entressola em Solyte (material mais leve do que o convencional EVA) para melhor propulsão com $21 \mathrm{~mm}$ de altura no calcanhar e $11 \mathrm{~mm}$ na parte frontal do pé.

- Calçado com tecnologia Adiprene: Cabedal em material sintético e tecido respirável. A entressola conta com os sistemas Adiprene (retropé) e Adiprene+ (antepé). Solado Adiwear composto de borracha de alta durabilidade e abrasão. 
- Calçado com tecnologia EVA: Possui cabedal em Nylon fechado, mas transpirável. Entressola de EVA injetado e densidades diferentes. Solado emborrachado que oferece mais aderência. Estabilizador inferior possui fibra de carbono. Lingueta macia e flexível. Palmilha anatômica removível que facilita a ventilação interna. Forro têxtil interno com reforço acolchoado no calcanhar.

A

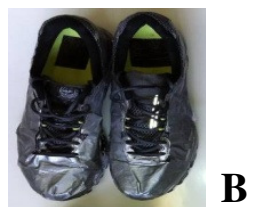

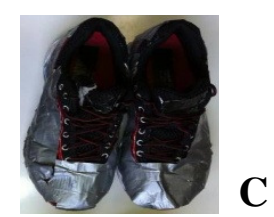

$\mathrm{C}$

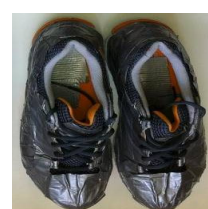

D

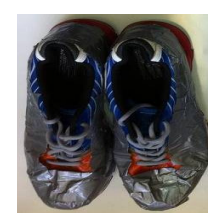

Figura 4- Calçados comercialmente disponíveis que foram analisados e comparados: A. Air, B. Gel, C. Adiprene, D. EVA $\neq$ densidades.

Tabela 1 - Especificações dos calçados testados neste estudo.

\begin{tabular}{|c|c|c|c|c|}
\hline $\begin{array}{l}\text { Especificações } \\
\text { (Tecnologia) }\end{array}$ & Air & Gel & Adiprene & $E V A$ \\
\hline Material da sola & Borracha & Borracha & Borracha & Borracha \\
\hline $\begin{array}{l}\text { Densidade do EVA } \\
\text { no retropé }\left(\mathrm{g} / \mathrm{cm}^{3}\right)\end{array}$ & 0,160 & 0,153 & 0,164 & 0,238 \\
\hline $\begin{array}{l}\text { Sistema de } \\
\text { absorção de } \\
\text { impacto no retropé } \\
\text { e antepé }\end{array}$ & $\begin{array}{c}\text { Câmara em } \\
\text { uretano com um } \\
\text { gás encapsulado } \\
\text { sob pressão }\end{array}$ & Unidades de Gel & $\begin{array}{c}\text { Adiprene (espuma } \\
\text { visco elástica) }\end{array}$ & $\begin{array}{c}\text { Camadas de } \\
\text { EVAde diferentes } \\
\text { densidades }\end{array}$ \\
\hline Tipo de pisada & Neutra & Neutra & Neutra & Neutra \\
\hline Massa calçado(g) & 309 & 263 & 322 & 320 \\
\hline
\end{tabular}




\subsection{Avaliação em campo - Etapa I}

\subsubsection{Avaliação Inicial}

Assim que o indivíduo chegava ao ambiente de coleta e após assinar o termo de consentimento, era aplicado um questionário previamente elaborado por meio de entrevista para caracterização dos corredores e esclarecimentos dos critérios de exclusão. Este questionário era dividido em quatro itens: dados pessoais, dados sobrea prática decorrida, dados sobre a utilização de calçados esportivos e dados sobre lesões relacionadas a corrida (ANEXO 3).

\subsubsection{Avaliação da postura estática do pé (FPI-6)}

Em seguida erafeitauma avaliação estática da postura do pé por meiodométodo Foot Posture Index - FPI6 (Redmond et al., 2006) (ANEXO 4), que é uma ferramenta de diagnóstico clínico destinado a quantificar o grau com que o pé pode ser considerado normal, pronado ou supinado.Estas avaliações foram feitas por uma única fisioterapeuta treinada, que atribuiu valores a uma série de observações realizadas em trêsregiões do pé (retropé, mediopé e antepé), onde valores positivos indicavam uma postura de pé pronado, valores negativos, uma postura de pé supinado, e valores próximos de zero ou zero, uma postura de pé neutra.

Os critérios utilizados para avaliação da postura do pé segundo o FPI-6 foram: palpação da cabeça do tálus, curvatura acima e abaixo do maléolo lateral, inversão e eversão do calcâneo, abdução e adução do antepé sobre o retropé, região talo navicular côncava ou abaulada e congruência do arco longitudinal medial. Cada 
um dos critérios observados era graduado em 0 para neutro, -2 para sinais claros de supinação e +2 para sinais claros de pronação. Estes valores eram então somados podendo variar entre $-12 \mathrm{a}+12$. Os valores de referência da postura estática do pé são então classificados em: neutro de 0 a +5 , muito pronado de +10 a +12 , muito supinado de -5 a -12 , pronado de +6 a +9 e supinado de -1 a -4 .

Foram aceitos para o estudo corredores com alinhamento do complexo tornozelo-pé neutro, supinado e pronado. Como previsto nos critérios de exclusão, não seriam incluídos os corredores que fossem classificados em muito supinado ou muito pronado, segundo os valores descritos anteriormente. Nenhum dos 28 corredores selecionados inicialmente foram desclassificados por este critério.

As medidas foram feitas com o corredor em bipedestação, com o peso corporal distribuído igualmente nos dois pés (Figura5). Cada pé foi avaliado eclassificado independentemente. Para garantir o mesmo alinhamento dos pés entre ossujeitos, também foi utilizado um pedaço de espuma de EVA de 7,5 $\mathrm{cm}$ entre os pésque delimitava a distância entre eles. 


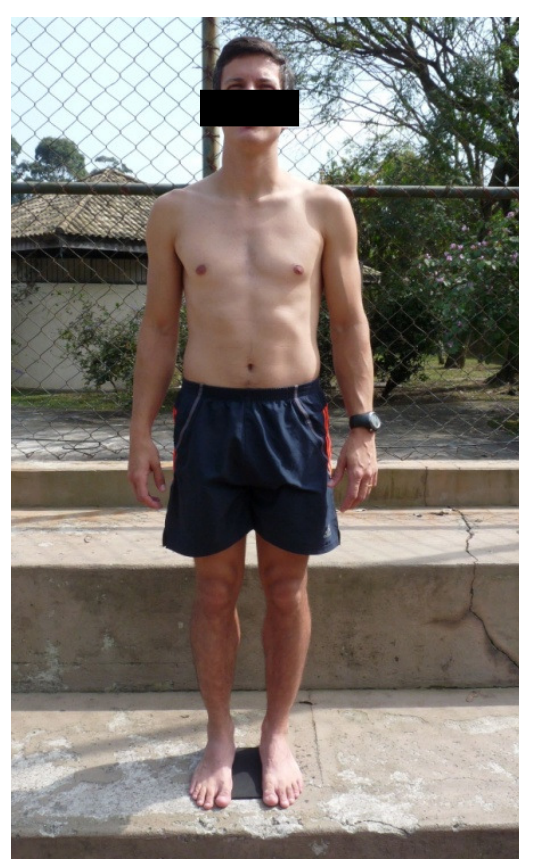

Figura 5 - Postura utilizada na avaliação do Foot Posture Index, com o corredor em pé, com os pés em paralelo e braços alinhados ao corpo.

\subsubsection{Avaliação do conforto}

As análises de conforto foram baseadas em uma escala analógica visual de 100 mm adaptada de Mündermann et al. (2002) (ANEXO 5), na qual no extremo do lado esquerdo é considerado desconfortável e no extremo do lado direito é considerado muito confortável. Os itens avaliados para cada calçado foram: amortecimento do calcanhar, conforto da borda superior do contraforte, conforto quanto à largura da base do contraforte, amortecimento no antepé, conforto na largura do antepé, conforto quanto ao comprimento do calçado, controle médiolateral durante a corrida, conforto da região do arco plantar, conforto geral.

As avaliações de conforto para cada calçado foram realizadas em duplo-cego, onde avaliadores e corredores não sabiam qual calçado estava sendo avaliado. Para que isso fosse possível, antes das coletasos calçados foram mascarados com fita prateada e spray preto; retiraram-se as etiquetas que os identificassem e realizou-se a 
abrasão do solado para eliminar qualquer identificação da marcado fabricante (Figura 6). Após este procedimento, os calçados foram numerados para que sua identificação até o final de todas as avaliações e análises estatísticas fossem sempre feitas por seu número correspondente e não mais pela marca, preservando o caráter cego da pesquisa. A ordem da avaliação de conforto dos quatro calçados foi sorteada para cada sujeito.

Os corredores eram instruídos a correr com cada calçado por aproximadamente 15 minutos (Figura7) e na sequência respondiam um questionário baseado nos itens de conforto e marcavam numa escala horizontal analógica o conforto de cada item para cada calçado avaliado. Terminada esta etapa, foi iniciada a coleta de pressão plantar em ambiente externo de treinamento.

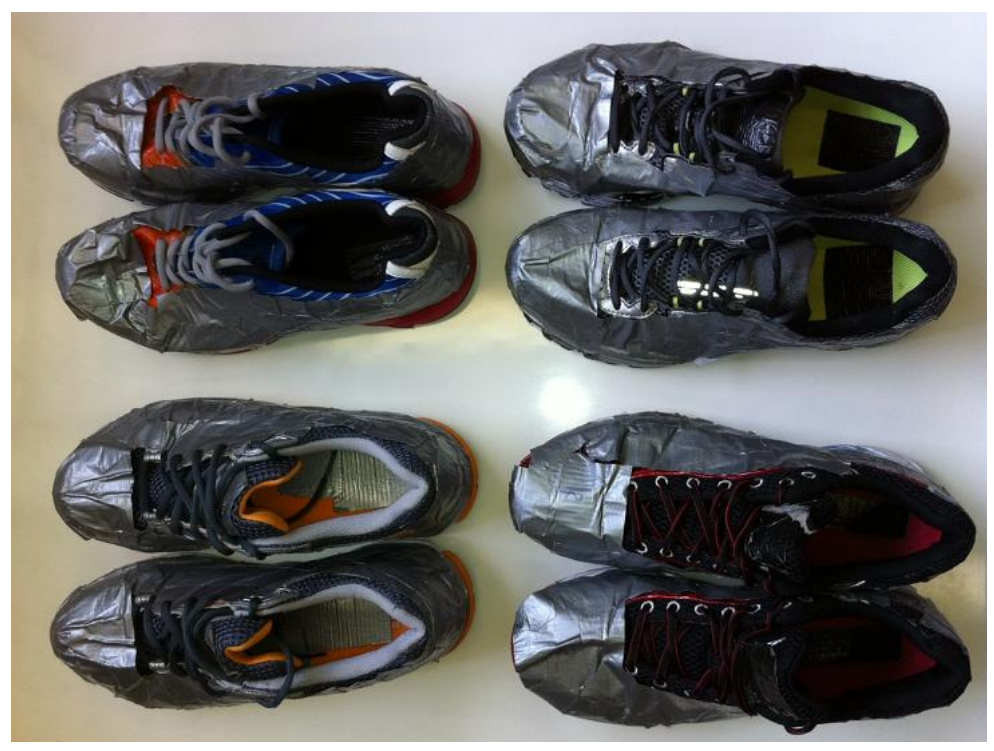

Figura 6 - Calçados utilizados nas coletas, mascarados com fita prateada e spray, etiquetas retiradas dos tênis e abrasão do solado. 


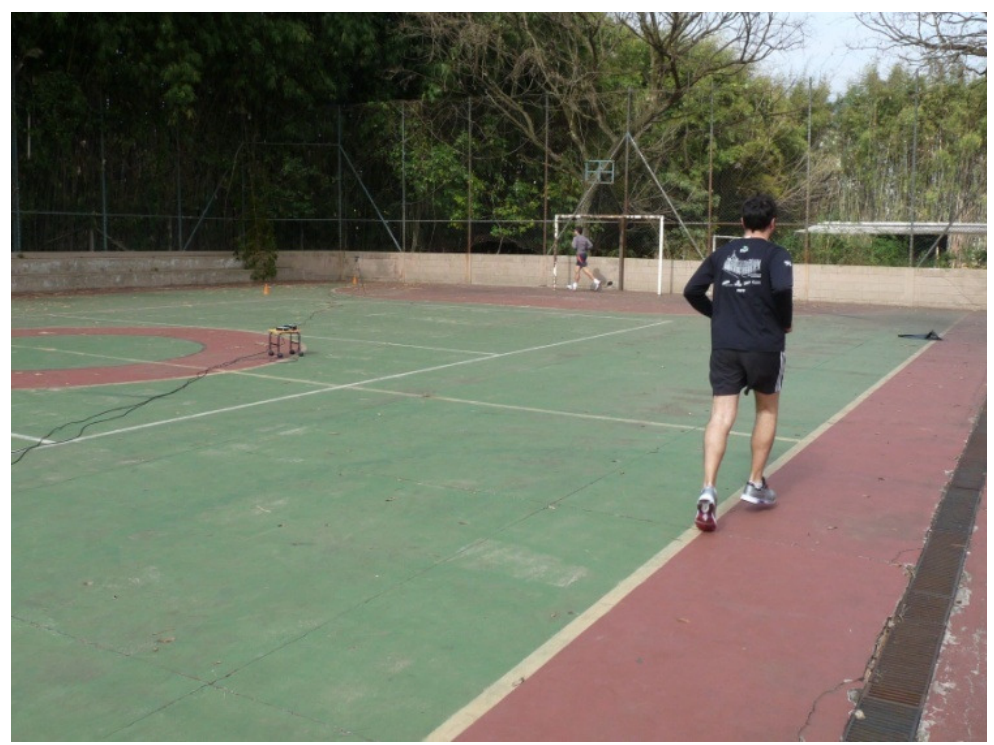

Figura 7 - Corrida de 15 minutos para avaliação da percepção de conforto dos calçados pelos corredoresem uma quadra plana da universidade de São Paulo.

\subsubsection{Avaliação da distribuição da pressão plantar}

A avaliação da distribuição da pressão plantar foi realizada utilizando-se o sistema Pedar X System (Novel, Munique, Alemanha) a uma frequência de amostragem de $100 \mathrm{~Hz}$. Este sistema é composto por palmilhas capacitivas de dois milímetros de espessura, cabos, unidade de sincronização (Figura8) e um calibrador. As palmilhas são compostas por 99 sensores capacitivos distribuídos homogeneamente, com resolução dependente do tamanho da palmilha, de aproximadamente 1 sensor $/ \mathrm{cm}^{2}$. As palmilhas se conectam a uma unidade sincronizadora condicionada em uma mochila pequena nas costas dos sujeitos cuja massa total é de $1,5 \mathrm{~kg}$, e a transmissão dos dados é feita via Bluetooth para o computador. Antes da colocação das palmilhas, cada sensor de cada palmilha foi calibrado com um aparato de compressão pneumática (Trublucalibrationdevice), de acordo com instruções do fabricante. 


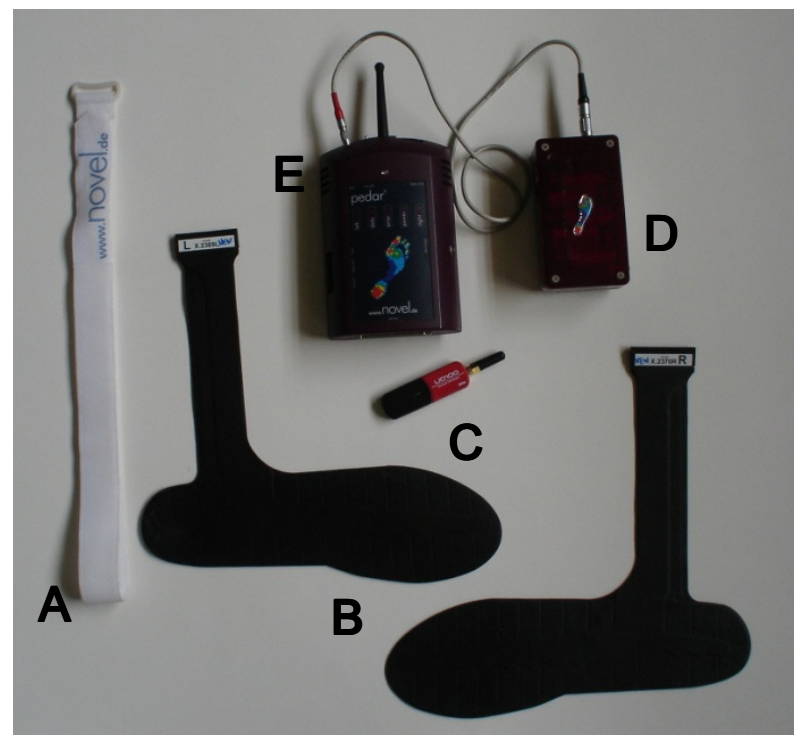

Figura 8 - Sistema Pedar X (Novel, Alemanha) composto por: (A) Fitas velcro para fixação dos cabos; (B) palmilha capacitiva; (C) Unidade de Bluetooth; (D) Bateria e (E) Condicionador de sinais.

Antes do início das coletas oscorredores fizeram uma corrida de familiarizaçãoaos equipamentos e a velocidade estabelecida para os testes. Esta familiarização teve como objetivo diminuir o efeito retroativo. Para esta etapa não foi necessária uma adaptação ao ambiente, uma vez que as coletas foram feitas em uma quadra dentro da cidade universitária, que é um local comum a prática esportiva. Esta avaliação também foi realizada em duplo-cego e a ordem dos sorteios dos calçados se manteve a mesma da avaliação de conforto.

Os corredores correram a uma velocidade de $12 \mathrm{~km} / \mathrm{h}$ e para assegurar que os mesmos estivessem dentro da velocidade estabelecida, as coletas foram monitoradaspor meio de dois sensores fotoelétricos dispostos no início e no final da área de coleta (CEFISE, Modelo Speed Test Fit, Nova Odessa, Brasil). Houve uma tolerância de $5 \%$ de variação na velocidade executada, devendo esta ser consistente entre as tentativas e entre os sujeitos. Os sujeitos correram em uma pista plana de 40 metrosde comprimentodelimitada na quadra (Figura 9). Foram considerados para a 
análise os passos executadosnos 20 metros intermediáriosdapista de 40 metros e dentro do limite de velocidade pré-estabelecido, totalizando aproximadamente 15 passos por corredor por calçado. A opção de analisar os 20 metros intermediários deveu-se ao fato de eliminar a fase de aceleração e desaceleração da corrida.

Não houve intervalos entre as tentativas, uma vez que os sujeitos selecionados para o estudo possuíam um volume de corrida semanal muito superior ao exigido no teste.

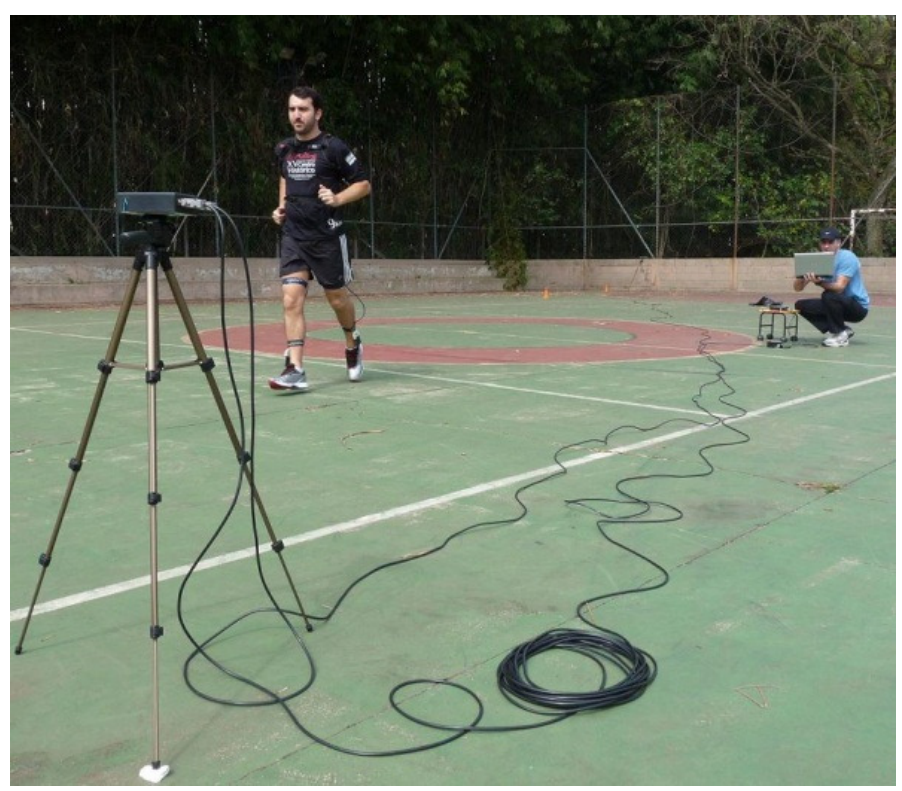

Figura 9 - Esquema de coleta em campo: 40 metros de pista, avaliação da corrida a12 $\mathrm{km} / \mathrm{h}( \pm 5 \%)$, monitorados por dois sensores fotoelétricos nos 20 metros intermediários usando os 4 modelos de calçados.

A superfície plantar foi divida em 3 grandes regiões para a análise da pressão plantar: retropé (30\% do comprimento do pé), mediopé (30\% do comprimento do pé), e antepé e dedos (40\% do comprimento do pé) (Figura10). 


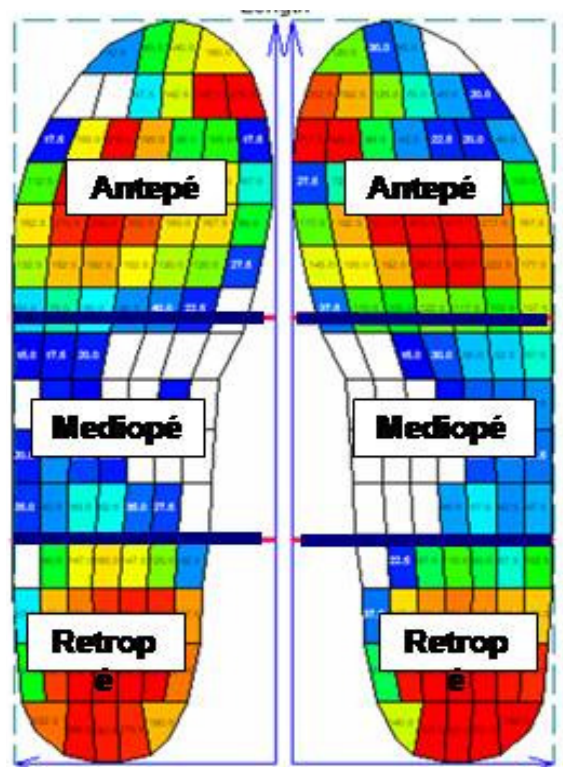

Figura 10 - Representação da divisão da superfície plantar em três áreas para a análise da distribuição da pressão plantar: retropé, mediopé e antepé.

As variáveis da distribuição da pressão plantar avaliadas foram:

- Área de contato do pé $\left(\mathrm{cm}^{2}\right)$ : representa a soma das áreas dos sensores pressionados a cada passo.

- Pico de pressão $(\mathrm{kPa})$ : representa o maior valor de pressão obtidos pelos sensores que compõem a área avaliada.

- Integral da pressão (kPa.s): representa o pico de pressão e o tempo para atingílo).

\subsection{Avaliação em Laboratório - Etapa II}

A segunda etapa da avaliação foi realizada dentro do Laboratório de Biomecânica do Movimento e Postura Humana (LaBiMPH) da Faculdade de Medicina da USP, no departamento de Fisioterapia, Fonoaudiologia e Terapia Ocupacional.Esta avaliação também foi realizada em duplo-cego, onde nem os 
corredores e nem os pesquisadores sabiam qual era o calçado avaliado, isso se manteve até a análise estatística. A ordem do sorteio dos calçados se manteve a mesma da primeira etapa. Os corredores deveriam voltar um segundo dia não consecutivo para o laboratório para finalizar o estudo.

Antes da coleta, os corredoresfizeram algumas corridas de adaptação no laboratório a fim de se habituar ao ambiente, à velocidade estabelecida e aos instrumentos. Cada corredor correu ao longo de uma superfície plana de 10 metros de comprimento (Figura11), a uma velocidade de $12 \mathrm{~km} / \mathrm{h}( \pm 5 \%)$, a mesma da etapa I. Para assegurar que os mesmos estivessem dentro da velocidade estabelecida, as coletas foram monitoradaspor meiode dois sensores fotoelétricos (CEFISE, Modelo Speed Test Fit, Nova Odessa, Brasil) dispostos a dois metros do centro da plataforma, totalizando quatros metros de distância total entre cada sensor.

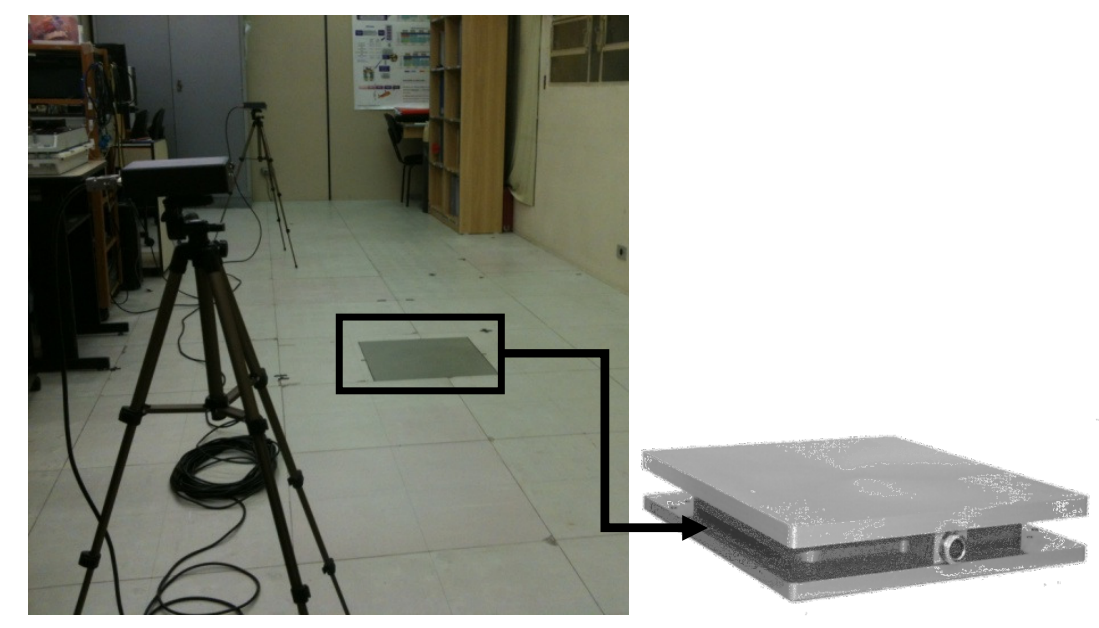

Figura 11 - Pista plana e regular de 10 metros no Laboratório de biomecânica, com a plataforma de força embutida no centro da pista, onde os corredores foram avaliados na segunda etapa do projeto.

Após a completa habituação ao laboratório, foram adquiridos 9 passos válidos para cada um dos calçados avaliados, garantindo uma confiabilidade dos dados cinéticos maiores que 0,93(Diss, 2001). 
A componente vertical da força reação do solo foi adquirida por meio de uma plataforma de força (AMTI OR-6-1000, Watertown, EUA), com dimensões de $47 \mathrm{~cm}$ x $51 \mathrm{~cm}$, nivelada com o solo, posicionada no centro da pista de 10 metros do laboratório e ajustada a uma frequência de amostragem de $1000 \mathrm{~Hz}$. Para aquisição dos dados foi utilizado um computador com placa A/D de aquisição de dados de 12bits (DT 3002, AMTI).

As variáveis da força reação do solo calculadas foram (Figura 12):

- primeiro pico da força vertical (Fz1) (normalizada pelo peso corporal - PC), equivalente ao momento do toque do calcanhar no solo;

- Segundo pico de força (Fz2) (PC), equivalente ao momento de propulsão;

- taxa de carga ouloading rate $80(\mathrm{LR} 80)(\mathrm{PC} / \mathrm{s})$, equivalente a taxa entre $20 \mathrm{e}$ $80 \%$ do primeiro pico da força vertical;

- taxa de carga ou loadingrate 100 (LR 100) (PC/s), equivalente a taxa de 0 a $100 \%$ do primeiro pico da força vertical;

- taxa de propulsão (Txp) (PC/s), definida como a taxa do segundo pico de força entre o tempo da força mínima até o segundo pico de força. 


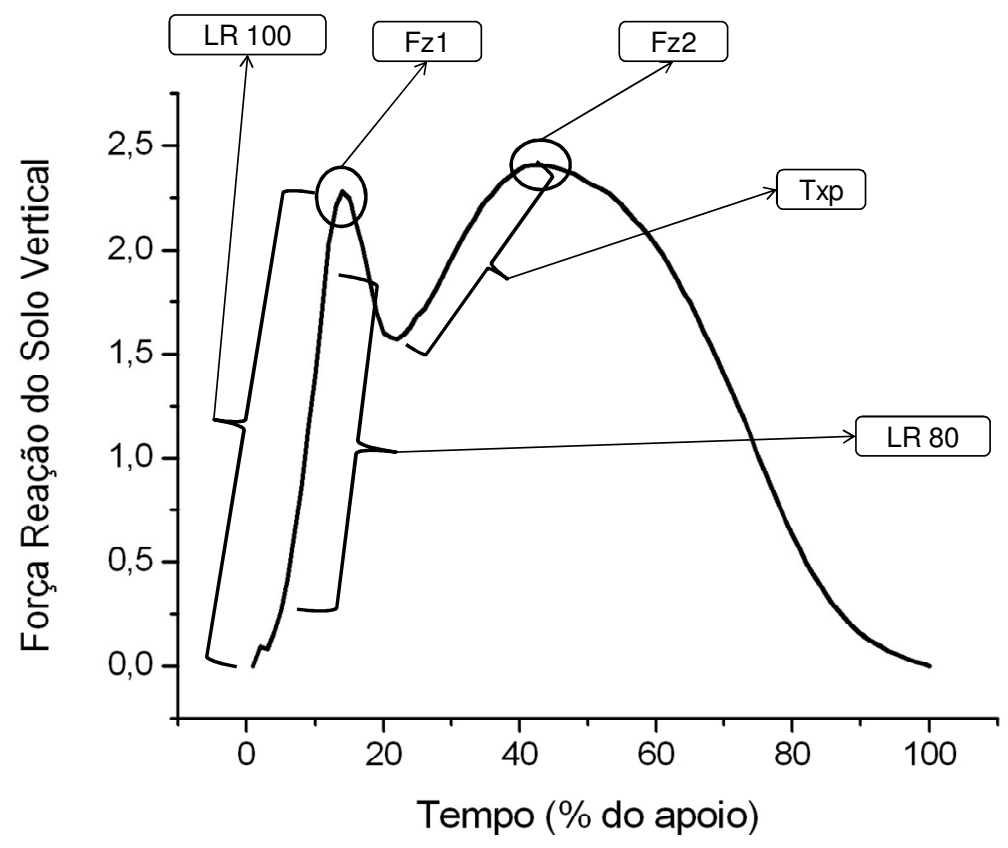

Figura 12 - Representação gráfica das variáveis daforçareação do solo vertical, onde (Fz1) $1^{\circ}$ pico vertical da força reação do solo, (Fz2) $2^{\circ}$ pico vertical da força reação do solo, (LR 80) taxa de carga entre 20 e $80 \%$ do $1^{\circ}$ pico vertical da força reação do solo, (LR 100) taxa de carga entre 0 e $100 \%$ do $1^{\circ}$ pico vertical da força reação do solo e (Txp) taxa de propulsão.

\subsection{Análise matemática dos dados}

O tratamento matemático dos dados de pressão plantar foi feito pelo Software da Novel Multiprojects. Após a exportação das variáveis já calculadas para cada área plantar em cada arquivo de coleta, noprograma Excel, foi calculado a média de aproximadamente 15 passos para cada calçado testado de cada variável estudada.

Os dados da plataforma de força foram exportados em formato ASCII, analisados em uma rotina personalizada em ambiente MatLab (versão R2009a) (APENDICE A),filtrados por um filtro passa baixa $4^{\circ}$ ordem tipo Butterworth com freqüência de corte de $300 \mathrm{~Hz}$,normalizados pelo peso corporal de cada corredor e na 
em função do tempo.Esta frequência foi escolhida após uma análise da Transformada Rápida de Fourier (FFT) das tentativas dos sujeitos.

\subsection{Análise estatística dos dados}

Por meio do software Statistica v.8 (StatSoft, Inc.), verificou-se a normalidade dasdistribuições das variáveis (teste de Shapiro-Wilk) e a homogeneidade de variâncias (teste Levene). Confirmados estes pressupostos, cada variável biomecânica ( 9 de pressão e 5 de força vertical, totalizando 14) e o valor da escala analógica de conforto, foram comparados entre os calçados por meio de ANOVAs para medidas repetidas, seguidas de pós teste de Neuman Keuls. Foi calculado o coeficiente de correlação de Pearson entre as variáveis biomecânicas (14) e o conforto geral, e entre asvariáveis biomecânicas e o amortecimento no retropé e no antepé, para cada calçado isoladamente e para todos os calçados sem distinguir as tecnologias. A correlação de Pearson foi considerada fraca entre 0 e 0,30; moderada ente 0,31 e 0,60; forte entre 0,61 e 0,90 e muito forte entre 0,91 e 1,0 (CallegariJacques, 2003). Foram consideradas diferenças estatísticas com nível de significância igual a $5 \%(\alpha=0,05)$.

O conjunto das 14 variáveis biomecânicas foireduzido para um grupo menor, restando apenas aquelas cujas correlações foram maiores ou igual a 0,20. Estas variáveis foram então introduzidas na análise de regressão stepwise backward a fim de determinar quais conjuntos de variáveis biomecânicas poderiam predizer o conforto geral do calçado. A análise de regressão foi feita para cada calçado separadamente. 
Em relação ao modelo para predizer o amortecimento do retropé, de seis variáveis relacionadas ao impacto no retropé, houve novamente uma redução das variáveis que entraram no modelo de regressão. E finalmente, das cinco variáveis relacionadas às cargas em antepé na fase de propulsão da corrida, houve novamente uma redução das variáveis que entraram no modelo de regressão para predizer o amortecimento percebido no antepé. As análises para predição do amortecimento do retropé e antepé foi feita para cada calçado separadamente. 


\section{RESULTADOS}

O calçado com EVA de diferentes densidades foi significativamente menos confortável quanto ao conforto geral em relação aos calçados Air (p=0,02), Gel $(\mathrm{p}=0,03)$ e Adiprene $(\mathrm{p}=0,01)$; quanto à largura do contraforte em relação aos calçados Gel $(\mathrm{p}=0,01)$ e Adiprene $(\mathrm{p}=0,02)$ e quanto ao controle médio lateral em relação a todos os modelos $(\mathrm{p}=0,01)$. Não houve diferença significativa entre os calçados quanto à percepção de amortecimento do retropé e antepé (p>0,05) (Figura 13).

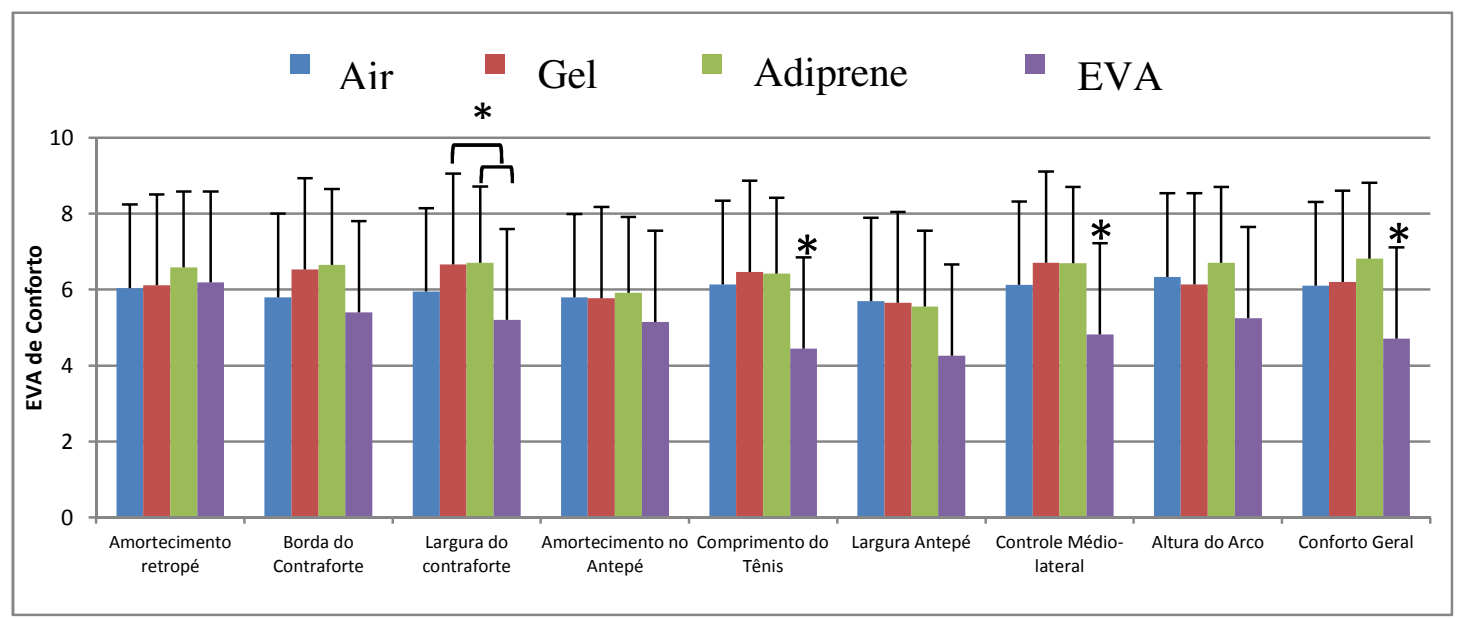

Figura 13 - Valores médios e desviopadrão obtidos da escala analógica da percepção de conforto dos calçados Air, Gel, Adiprene e EVA. *representa diferença estatística entre os calçados sinalizados.

O calçado Gel apresentou o primeiro pico significativamente maior em relação ao calçado Air $(\mathrm{p}=0,03)$ e Adiprene $(\mathrm{p}=0,01)$. A taxa de carga 100 foi significativamente menor no calçado Adiprene em relação ao calçado Gel ( $\mathrm{p}=0,02)$, (tabela 2). Oprimeiro pico e a taxa de carga 100 foram 7,2\% e 9,5\% menores, respectivamente, no calçado Adiprene em relação ao Gel. 
Tabela 2 - Médias e desvio padrão das variáveis da força reação do solo vertical normalizada pelo peso corporal (PC) dos quatro modelos de calçados analisados.

\begin{tabular}{|c|c|c|c|c|c|}
\hline & Air & Gel & Adiprene & $E V A$ & $\mathbf{p}^{1}$ \\
\hline $1^{\circ}$ Pico vertical (PC) & $1,84 \pm 0,30^{\#}$ & $1,94 \pm 0,35^{\# *}$ & $1,81 \pm 0,28^{*}$ & $1,88 \pm 0,32$ & 0,008 \\
\hline Taxa de carga $80\left(\mathrm{~N} \cdot \mathrm{ms}^{-1}\right)$ & $70,51 \pm 18,58$ & $69,63 \pm 21,12$ & $65,71 \pm 16,24$ & $67,14 \pm 15,85$ & 0,167 \\
\hline Taxa de carga $100\left(\mathrm{~N} \cdot \mathrm{ms}^{-1}\right)$ & $54,46 \pm 13,00$ & $56,21 \pm 14,91^{*}$ & $51,25 \pm 10,96^{*}$ & $53,38 \pm 11,57$ & 0,025 \\
\hline $2^{\circ}$ Pico vertical $(\mathrm{PC})$ & $2,49 \pm 0,19$ & $2,50 \pm 0,21$ & $2,49 \pm 0,20$ & $2,50 \pm 0,18$ & 0,878 \\
\hline Taxa de Propulsão $\left(N \cdot m^{-1}\right)$ & $15,95 \pm 3,20$ & $15,23 \pm 3,17$ & $15,59 \pm 2,93$ & $15,78 \pm 2,35$ & 0,539 \\
\hline
\end{tabular}

TANOVA para medidas repetidas. " representa a diferença estatística entre os calçados sinalizados. *representa diferença estatística entre os calçados sinalizados.

O calçado Adiprene apresentou pico de pressão no antepé significativamente menor em relação aos calçados Air (p<0,001), Gel $(\mathrm{p}<0,001), E V A(\mathrm{p}<0,001)$ e menor integral da pressão no antepé em relação aos calçados Air (p<0,001), Gel $(\mathrm{p}<0,001)$ e $E V A(\mathrm{p}<0,001)$. O calçado $E V A$ apresentou pico e integral da pressão $(\mathrm{p}<0,001)$ no retropé significativamente maiores em relação a todos os outros calçados (tabela 3).

As correlações do produto de Pearson entre as variáveis biomecânicas e o conforto geral e percepção de amortecimento do retropé e antepé não apresentaram correlações significativas para os quatro modelos de calçados foram analisados separadamente e agrupados sem distinção das tecnologias. 
Tabela 3 - Médias e desvio padrão da área de contato, pico de pressão e integral da pressão para cada região da superfície plantar durante a corrida com os quatro modelos de calçados.

\begin{tabular}{|c|c|c|c|c|c|c|c|}
\hline & Calçados & $\begin{array}{l}\text { Área } \\
\left(\mathrm{cm}^{2}\right)\end{array}$ & $p^{1}$ & $\begin{array}{c}\text { Pico pressão } \\
(\mathbf{k P a})\end{array}$ & $\mathbf{p}^{1}$ & $\begin{array}{c}\text { Integral } \\
\text { (kPa.s) }\end{array}$ & $\mathbf{p}^{1}$ \\
\hline \multirow{4}{*}{ Retropé } & Air & $40,7 \pm 0,3$ & \multirow{4}{*}{$\begin{array}{l}F=0,9 \\
p=0,467\end{array}$} & $242,7 \pm 40,8$ & & $18,2 \pm 3,0$ & \multirow{4}{*}{$\begin{array}{l}\mathrm{F}=32,9 \\
\mathrm{p}<0,00\end{array}$} \\
\hline & Gel & $40,6 \pm 0,5$ & & $239,5 \pm 40,0$ & $\mathrm{~F}=141,3$ & $18,3 \pm 4,1$ & \\
\hline & Adiprene & $40,7 \pm 0,3$ & & $246,5 \pm 51,6$ & $\mathrm{p}<0,001$ & $18,2 \pm 3,5$ & \\
\hline & $E V A$ & $40,6 \pm 0,4$ & & $303,0 \pm 54,2^{\mathrm{c}}$ & & $21,6 \pm 3,6^{\mathrm{c}}$ & \\
\hline \multirow{4}{*}{ Médiopé } & Air & $42,0 \pm 3,3$ & \multirow{4}{*}{$\begin{array}{l}F=53,1 ; \\
p<0,001\end{array}$} & $126,2 \pm 32,9^{\# \$}$ & & $16,6 \pm 5,3$ & \multirow{4}{*}{$\begin{array}{l}F=28,6 ; \\
p<0,001\end{array}$} \\
\hline & Gel & $42,7 \pm 2,7$ & & $141,7 \pm 38,0^{\# *}$ & $F=16,8$ & $18,7 \pm 5,7^{\mathrm{d}}$ & \\
\hline & Adiprene & $42,7 \pm 2,3$ & & $136,2 \pm 28,5^{\$ \epsilon}$ & $\mathrm{p}<0,001$ & $17,8 \pm 4,8^{\mathrm{b}}$ & \\
\hline & $E V A$ & $39,0 \pm 4,7^{\mathrm{c}}$ & & $124,3 \pm 38,1^{* \epsilon}$ & & $15,2 \pm 5,9$ & \\
\hline \multirow{4}{*}{ Antepé } & Air & $70,4 \pm 0,4$ & & $313,1 \pm 54,9$ & & $44,4 \pm 8,2^{\mathrm{a}}$ & \multirow{4}{*}{$\begin{array}{l}F=49,7 ; \\
p<0,001\end{array}$} \\
\hline & Gel & $70,1 \pm 0,8$ & $\mathrm{~F}=2,0$ & $306,7 \pm 63,9$ & $\mathrm{~F}=33,7$ & $43,3 \pm 8,0$ & \\
\hline & Adiprene & $70,4 \pm 0,4$ & $\mathrm{p}=0,107$ & $279,1 \pm 56,8^{b}$ & $\mathrm{p}<0,001$ & $39,0 \pm 7,7^{\mathrm{b}}$ & \\
\hline & $E V A$ & $70,3 \pm 0,9$ & & $314,8 \pm 68,2$ & & $43,1 \pm 9,1$ & \\
\hline
\end{tabular}

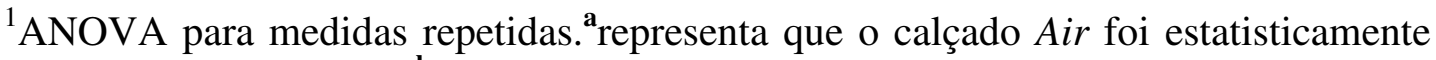
diferente dos demais, 'bepresenta que o calçado Adiprene foi estatisticamente diferente dos demais, 'representa que o calçado EVA foi estatisticamente diferente dos demais, ${ }^{d}$ representa que o calçado Gel foi estatisticamente diferente dos demais. \# representa diferença estatística entre calçados Air e Gel. \$representa diferença estatística entre calçados Air e Adiprene. ${ }^{\&}$ representa diferença estatística entre tênis Gel e Adiprene. "representa diferença estatística entre tênis Gel e EVA. ${ }^{€}$ representa diferença estatística entre tênis Adiprene e EVA.

O modelo de regressão linear múltipla para predizer o conforto geral do calçado reduziu a dimensionalidade das variáveispara 8 (pico de pressão no antepé, integral da pressão no antepé, área de contato no antepé, taxa de carga 80, taxa de carga 100, primeiro e segundo pico e o taxa de propulsão),baseado no índice de correlação de Pearson maior ou igual a 0,20. Somente o modelo obtido para o 
calçado Adiprene foi significativo ( $\mathrm{p}=0,015)$, apresentando um $\mathrm{R}=0,75$ e $\mathrm{R}_{\text {ajustado }}^{2}=0,56$. Este modelo revelou que $56 \%$ do conforto percebido pelo usuário podem serexplicados pelas variáveis taxa de propulsão $($ Beta $=0,620)$ e integral da pressão no antepé (Beta=1,150). Não houve significância estatística nos modelos de predição de conforto geral para os outros calçados.

Em relação aos modelos de regressão para predição do amortecimento percebido em retropé e antepé, somente o modelo para predizer o amortecimento percebido em antepé do calçado Adiprene foi significativo $(\mathrm{p}=0,016)$, apresentando um $\mathrm{R}=0,63$ e $\mathrm{R}^{2}{ }_{\text {ajustado }}=0,33$. Este modelo revelou que $33 \%$ da percepção de amortecimento no antepépodem serexplicados pelas variáveis segundo pico de força (Beta=-0,72) e taxa de propulsão (Beta=0,77). 


\section{DISCUSSÃO}

Este estudo buscou identificar as relações entre o conforto geral, amortecimento percebido e as variáveis biomecânicas durante a corrida com quatro diferentes tecnologias de amortecimento de calçados esportivos. De maneira geral, os resultados mostraram que o calçado com EVA de diferentes densidades foi avaliado como o de pior conforto, independente das regiões do calçado, e com uma das menores taxas de carga, similar aos calçados Adiprene e Air, tal como previa nossa primeira tese. Dentre os calçados com tecnologias de amortecimento de impacto, o calçado Adiprene foi avaliado como o de melhor conforto, independente da região do calçado, e a menor taxa de carga 100, embora, sem diferença estatística em relação aos calçados EVA e Air, confirmando nossa segunda tese. Porém, não houve correlação entre o conforto ou amortecimento percebido e as variáveis relacionadas ao impacto para nenhum calçado, diferentemente do que previa nossa terceira tese. Cinqüenta e seis por cento do conforto geral foi predito por duas variáveis biomecânicas relacionadas ao impacto (taxa de propulsãoe integral da pressão no antepé), e $33 \%$ da percepção de amortecimento no antepé foi predito por duas variáveis biomecânicas (taxa de propulsãoe segundo pico força) somente para o calçado com tecnologia Adiprene.

O conforto geral percebido pelos corredores não foi diferente entre os calçados com adição de tecnologia para amortecimento de impacto (Gel, Air e Adiprene). Uma possível explicação para este resultado foi a similaridade entre as características das entressolas destas três construções cuja densidade da composição 
de EVA foi bem semelhante (Gel: $0,153 \mathrm{~g} / \mathrm{cm}^{3}$; Air: $0,160 \mathrm{~g} / \mathrm{cm}^{3}$ e Adiprene: 0,164 $\left.\mathrm{g} / \mathrm{cm}^{3}\right)$. A maior dureza da entressola do calçado $E V A\left(0,238 \mathrm{~g} / \mathrm{cm}^{3}\right)$ pode ter gerado maior desconforto nos corredores.Outro fator importante que pode ter influenciado a percepção de conforto do calçado EVA com diferentes densidades é o baixo conforto percebido pelos corredores quanto ao controle médio-lateral, que pode ter indicado que a área de contato dos pés foi menor neste calçado e consequentemente alterado a percepção destes corredores, resultando numa avaliação geral de conforto negativa.

As percepções de conforto nas regiões do retropé e antepé também não apresentaram diferenças significativas entre os calçados. Hennig e Sterzing (2009) demonstraram por meio de um mapeamento de sensibilidade do pé humano, que o calcanhar foi a região com menor sensibilidade ao toque e que as variações no material da entressola podem não favorecer o controle do equilíbrio dinâmico (Perry et al., 2007). Portanto, quando diferentes sistemas de amortecimento são introduzidos nesta região do calçadooscorredores não são capazes de identificar diferenças na percepção de conforto, principalmente na região do retropé.

Nossos resultados mostraram que não há uma variável relacionada ao impacto que possa estar relacionada ao conforto geral ou percepção de amortecimento. Somente dois estudos prévios da década de 90, mostraram uma relação entre percepção de amortecimento e variáveis biomecânicas (Hennig et al., 1996; Milani et al., 1997). Tanto Milani et al. (1997) quanto Hennig et al. (1996) mostraram uma relação entre a percepção de amortecimento e as variáveis da força reação do solo e pressão plantar durante o correr com calçados predominantemente de EVA com diferentes durezas de entressola. Ambos os estudos encontraram menores taxas de cargaem calçados avaliados como mais duros. No presente estudo, esta relação só 
sepreservou no calçado com tecnologia de EVA, mas não nos calçados com adição de materiais na entressola com a finalidade de melhorar a atenuação das cargas, os quais não foram estudados por Milani et al. (1997) e Hennig et al. (1996). Portanto, estes materiais inseridos na entressola com tecnologia de atenuação de impacto muda a relação entre as respostas biomecânicas e a percepção que o corredor tem da capacidade de amortecimento e do conforto geral desse calçado.

Já Chen e Nigg (1994) demonstraram que a integral e o pico de pressão são sensíveis para representar as diferenças no conforto quando se avalia diferentes palmilhas, mas somente durante o andar, não se repetindo essa relação no correr. Wegener et al.(2008) não encontraram relação entre oconforto geral do calçado esportivo e pressão plantar durante a corrida em corredores com pés cavos. Jordan et al.(1997) também não observaram relação entre pressão e conforto percebido em 15 participantes que andaram com uma variedade de calçados casuais.

Embora o conforto seja um importante fator para a compra do calçado esportivo entre corredores recreacionais, nossos resultados adicionados aos inconsistentes encontrados na literatura, não permitem concluir como o conforto ou as percepções de amortecimento dos calçados esportivos se relacionam com variáveis biomecânicas que representam o impactoe que podem estar associadas às lesões em corredores (Milner et al., 2006; Crowell e Davis, 2011).

A interação dos materiais da entressola, do modelo do calçado e do corredor, dificulta a previsão de como um indivíduo pode reagir a um dado calçado esportivo (Frederick, 1986). Isto também pode explicar porque tem sido difícil estabelecer conexões diretas entre o calçado, as forças de impacto e as lesões. Um melhor esclarecimento dessa relação poderia trazer benefícios para a construção do calçado 
de corrida, tanto para a melhora do conforto quanto para diminuição de taxas de cargas durante a corrida.

Outro achado interessante deste estudo foi a predição do conforto geral pelas variáveis taxa de propulsão e integral da pressão, e predição da percepção de amortecimento no antepé pelas variáveis taxa de propulsãoe segundo pico da força vertical, porém somente para a tecnologia Adiprene, tecnologia esta avaliada como a de maior conforto e maciez pelos corredores e de menor densidade da entressola juntamente com as Air e Gel, diferindo da tecnologia de EVA avaliada como a de menor conforto, maior dureza e maior densidade de entressola.

Contrariamente a esses achados, Henniget al. (1996) encontraram que em calçados mais macios observou-se maiores picos de pressão no calcanhar e taxas de força em relação a calçados mais duros. Milani et al.(1997) também observaram que quanto maior o amortecimento, maiores foramas taxas de carga. Tanto Hennig et al. (1996) quanto Milani et al.(1997) apóiam a idéia que baseado nas habilidades de percepção de cada corredor, há uma adaptação da técnica de corrida com calçados mais duros para evitar as altas cargas de impacto no calcanhar. Nossos resultados podem indicar que com base nestas habilidades, essas adaptações não ocorrem somente em calçados com entressola mais rígida, mas em calçados com entressolas mais macias, já que os calçados não se diferenciaram expressivamente nas variáveis biomecânicas. Nurse et al. (2005) demonstraram que a mudança da textura do calçado provocou mudanças no padrão cinemático da marcha. Desta forma, as diferenças das construções e tecnologias dos calçados avaliados podem ter gerado sutis ajustes cinemáticos nos corredores a ponto de mascarar as diferenças nas variáveis de impacto mensuradas na interface calçado-pé. Estes ajustes cinemáticos 
poderiam ser avaliados em estudos futuros acrescidos de uma avaliação cinemática de membros inferiores.

Em resumo, dependendo da tecnologia de amortecimento, o calçado com melhor percepção de conforto e maciez também pode gerar menores taxas de carga, porém não podemos inferir que o resultado encontrado para a tecnologia Adiprene se reproduza em outras tecnologias existentes no mercado. Cabe destacar também que só avaliamos quatro tecnologias de calçados dentro de um universo com dezenas de possibilidades de construção existentes, portanto temos que ter cautela ao transferir os nossos resultados a outras tecnologias, mesmo que semelhantes à testada.

Uma limitação deste estudo foi que não avaliamos outros elementos estruturais do calçado que podem interferir na percepção de conforto e de amortecimento, tais como os tipos de costura, o cabedal, a quantidade de tecidos utilizados na construção e os diferentes padrões de enlaçamento. Futuras pesquisas envolvendo a relação entre conforto e variáveis biomecânicas poderiam ser feitas envolvendo estas características de construção de calçados esportivos. 


\section{CONCLUSÃO}

Os resultados do presente estudo não mostraram relação entre as variáveis biomecânicas e a percepção de conforto para três das quatro diferentes tecnologias de amortecimento estudadas (Gel, Air e EVA com diferentes densidades). Somente o calçado com tecnologia Adiprene teve seu conforto geral e a percepção de amortecimento predita pelas cargas em antepé. Assim, de maneira geral, não se pode predizer o conforto geral e a percepção de amortecimento de um calçado de corrida por meio do impacto e da pressão plantar recebidos. 


\section{ANEXO 1- Termo de Consentimento Livre Esclarecido}

DADOS DE IDENTIFICAÇÃO DO SUJEITO DA PESQUISA OU RESPONSÁVEL LEGAL

1. NOME: :-

DOCUMENTO DE IDENTIDADE $\mathrm{N}^{\circ}$ : SEXO :.M $\square \mathrm{F} \square$

DATA NASCIMENTO: ........................

ENDEREÇO. .. $\mathrm{N}^{\circ}$ APTO:

BAIRRO:. CIDADE.

CEP:. TELEFONE: DDD

TÍTULO DO PROTOCOLO DE PESQUISA: Variáveis biomecânicas relacionadas ao impacto e percepção de conforto em calçados de corrida com diferentes tecnologias de amortecimento. PESQUISADOR: (1) ROBERTO C. DINATO E (2) ISABEL DE CAMARGO NEVES SACCO CARGO/FUNÇÃO: (1) EDUCADOR FÍSICO (2) PROF. DRA DO CURSO DE FISIOTERAPIAUNIDADE DO HCFMUSP: DEPT. DE FISIO, FONO E T.O.

3. AVALIAÇÃO DO RISCO DA PESQUISA:

RISCO MÍNIMO (x) RISCO MÉDIO () RISCO BAIXO () RISCO MAIOR () 4.DURAÇÃO DA PESQUISA : 18 MESES

Objetivo do estudo: O objetivo deste estudo será investigar a influência do calçado esportivo no conforto percebido, na distribuição da pressão plantar e no impacto, como forma de identificar as variáveis mais sensíveis à mudança das características de amortecimento do calçado.

Explicação do procedimento: O Senhor (a) será entrevistado por meio de um questionário que fornecerá informações pessoais tais como nome, data de nascimento, telefone, massa, altura e informações sobre corrida. Será feita medida do pé, tais como: circunferência, comprimento, largura e altura do arco. Correrá com quatro modelos de tênis utilizando palmilhas especificas que medem a pressão plantare preencherá uma escala de conforto de cada calçado.

Duração do experimento: os testes terão a duração de aproximadamente quarenta minutos.

Benefícios: Espera-se que haja uma diferença entre os resultados dos dois métodos e com isso poderemos ajudar a selecionar e identificar o calçado mais apropriado a pratica da corrida.

Desconforto e risco: o experimento não será invasivo e não envolve qualquer risco à sua saúde.

Liberdade de participação: a sua participação neste estudo é voluntária, o sr/sra tem o direito de interrompê-la a qualquer, e sua identidade não será revelada. $\mathrm{O}$ (a) senhor (a) tem o direito de fazer 
qualquer pergunta nos intervalos do experimento. Os pesquisadores se prontificam em responder todas as questões sobre o experimento. Sua participação neste estudo é de livre e espontânea vontade.

É seu direito manter uma cópia deste consentimento. Em qualquer etapa do estudo, você terá acesso aos profissionais responsáveis pela pesquisa para esclarecimento de eventuais dúvidas. A orientadora e coordenadora do laboratório de Biomecânica, Dra. Isabel de Camargo Neves Sacco que pode ser encontrado no endereço Rua Cipotânea, 51, Cidade Universitária, CEP: 05360-160 São Paulo. Telefone 3091-8426. Se você tiver alguma consideração ou dúvida sobre a ética da pesquisa, entre em contato com o Comitê de Ética em Pesquisa (CEP) -Av. Dr. Arnaldo, 455 - Instituto Oscar Freire $-1^{\circ}$ andar- tel.: 3061-8004 FAX: 3061-8004-E-mail: cep.fmusp@ hcnet.usp.br.

Data

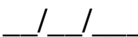

Assinatura do paciente

Assinatura do pesquisador 


\title{
ANEXO 2 - APROVAÇÃO DO COMITÊ DE ÉTICA EM PESQUISA
}

\author{
Till 1 II \\ MEDICINA \\ COMITÊ DE ÉTICA EM PESQUISA
}

\section{CIÊNCIA}

O Comitê de Ética em Pesquisa da Faculdade de Medicina da Universidade de São Paulo, em 18 de Março de 2013, TOMOU ClÊNCIA do(s) documento(s) abaixo mencionado(s) no Protocolo de Pesquisa $n^{\circ}$ 329/11, intitulado: "INVESTIGAÇĀO DA INFLUÊNCIA DO CALÇADO ESPORTIVO NA PERCEPÇÃo do CONFORTO E NAS VARIÁVEIS CINÉticas NA CORRIDA" apresentado pelo FISIOTERAPIA, FONOAUDIOLOGIA E TERAPIA OCUPACIONAL.

- Carta de 05.03.13 referente a Mudança de título para - Variáveis biomecânicas relacionadas ao impacto e percepção de conforto em calcadps de corrida com diferentes tecnologias de amortecimento

Pesquisador (a) Responsável: Isabel de Camargo Neves Sacco

Pesquisador (a) Executante: Roberto Casanova Dinato

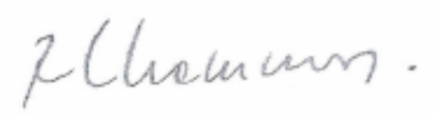

Prof. Dr. Roger Chammas

Coordenador

Comitê de Ética em Pesquisa 


\section{ANEXO 3 - FICHA DE AVALIAÇÃO INICIAL}

DADOS PESSOAIS Data da avaliação:

Nome: Identificação:

Data de nascimento: Idade: Sexo:

Telefone: e-mail:

Massa:

Altura:

IMC:

Há quanto tempo você corre? anos

Freqüência por semana: vezes

Tempo dos 10Km: $\operatorname{mim}$

Volume de treino semanal: $\mathrm{Km}$

Qual tênis usa para treinar

Utilização do tênis para:

( )mesmo para treino e prova

( ) 2 tênis revezamento simples

( ) 2 tenis -1 treino e 1 prova

( )3tenis -2 treino e 1 prova

Já apresentou lesão no ultimo ano?

( ) $\mathrm{Sim}$

( )Não

( ) tendinite onde? ( )calcâneo ( ) intra patelar

( ) supra patelar

( ) fasciite plantar D/E

( ) esporão do calcâneo

( ) fratura de estresse nos ossos do pé

( ) torção do tornozelo

( ) síndrome do trato ílio tibial D/E

( ) lesões ligamentares joelho D/E

( ) lesões meniscais D/E L/M

( ) fratura de estresse na tíbia D/E

Você utiliza palmilhas para correr?

( ) $\mathrm{Sim}$

( ) Não

Você utiliza tornozeleira para correr?

( ) $\mathrm{Sim}$

( ) Não 
ANEXO 4 - Avaliação Antropométrica pelo Método FPI

Nome:

Sujeito:

Data:

\begin{tabular}{|c|c|c|c|c|}
\hline FOTOS & FATOR & $\begin{array}{l}\text { PLANO DE } \\
\text { VISÃO }\end{array}$ & \multicolumn{2}{|c|}{ Pontuação } \\
\hline & & & MIE $-2 a+2$ & MID $-2 \mathrm{a}+2$ \\
\hline & $\begin{array}{l}\text { Palpação da } \\
\text { Cabeça Talar }\end{array}$ & $\begin{array}{c}\text { Transverso } \\
\text { retropé }\end{array}$ & & \\
\hline & $\begin{array}{l}\text { Curvas acima e } \\
\text { abaixo do } \\
\text { maléolo lateral }\end{array}$ & $\begin{array}{l}\text { Frontal/ } \\
\text { Transverso } \\
\text { Retro-pé }\end{array}$ & & \\
\hline & $\begin{array}{c}\text { Inversão/Eversão } \\
\text { do calcâneo }\end{array}$ & $\begin{array}{l}\text { Frontal } \\
\text { Retro-pé }\end{array}$ & & \\
\hline & $\begin{array}{l}\text { Proeminência na } \\
\text { região da } \\
\text { articulação Talo- } \\
\quad \text { Navicular }\end{array}$ & $\begin{array}{l}\text { Transverso } \\
\text { ante-pé }\end{array}$ & & \\
\hline & $\begin{array}{l}\text { Congruência do } \\
\text { arco longitudinal } \\
\text { medial }\end{array}$ & $\begin{array}{l}\text { Sagital } \\
\text { ante-pé }\end{array}$ & & \\
\hline & $\begin{array}{l}\text { Abdu/adu do ante- } \\
\text { pé sobre o retro-pé }\end{array}$ & $\begin{array}{l}\text { Transverso } \\
\text { Ante-pé }\end{array}$ & & \\
\hline & & TOTAL & & \\
\hline
\end{tabular}

ComprimentodeMMIIMIE:

MID: 
ANEXO 5 - FICHA DE COLETA DOS DADOS DE CONFORTO

\begin{tabular}{|c|c|c|c|c|}
\hline \multicolumn{2}{|l|}{ Ident. Sujeito_ } & \multicolumn{2}{|c|}{ Data___ _ } & \\
\hline \multicolumn{4}{|l|}{ Nome: } & \\
\hline \multirow{2}{*}{\multicolumn{5}{|c|}{ Palmilha:___ Examinador: }} \\
\hline & & & & \\
\hline Tênis & Tempo tentativa 1 & Tempo tentativa 2 & Tempo tentativa 3 & Tempo Tentativa 4 \\
\hline No.: & / & / & / & / \\
\hline
\end{tabular}

1. Amortecimento do Calcanhar: Qual a sua percepção de conforto para a rigidez ou maciez na região do calcanhar?

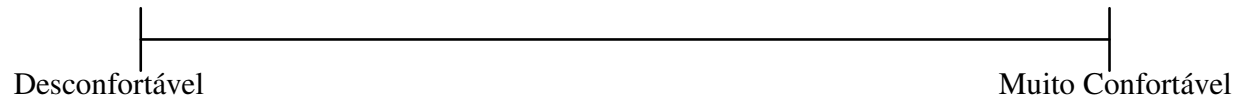

2. Borda Superior do Contraforte: Qual o conforto da borda superior do contraforte do tênis?

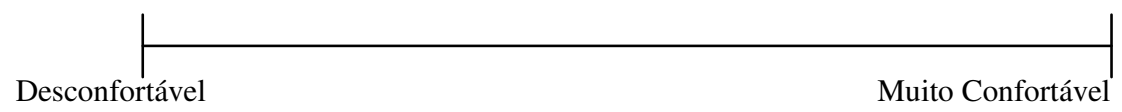

3. Largura do Contraforte: Qual o conforto da largura do contraforte do tênis no calcanhar?

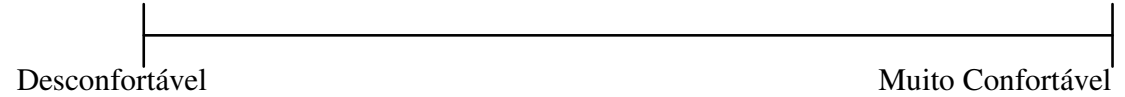

4. Amortecimento do Antepé:Qual a sua percepção de conforto para o quesito amortecimento na região do antepé?

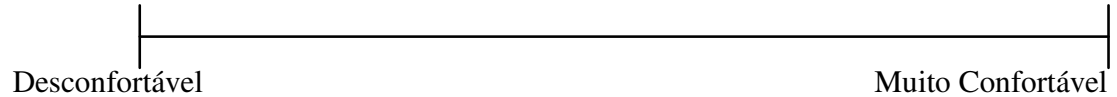

5. Largura do Antepé: Qual o conforto da largura do antepé?

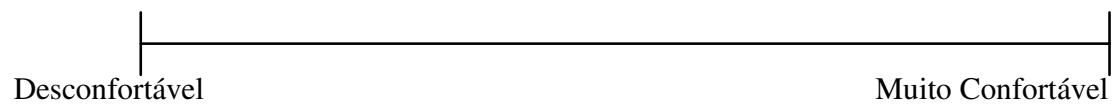

6. Comprimento do tênis: Qual o conforto do comprimento do tênis no calcanhar?

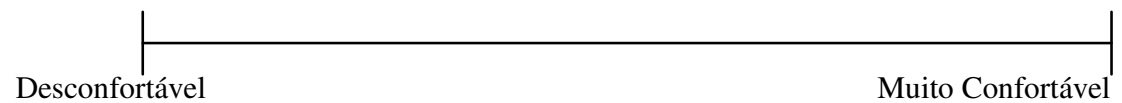

7.Controle Médio-lateral: Qual o conforto na movimentação médio-lateral do calçado?

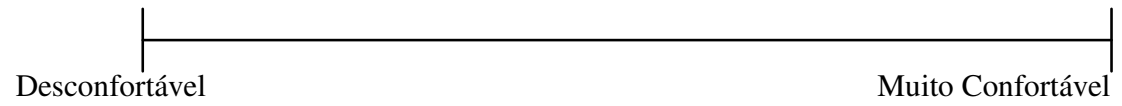

8. Altura do arco:Qual o conforto da altura do arco?

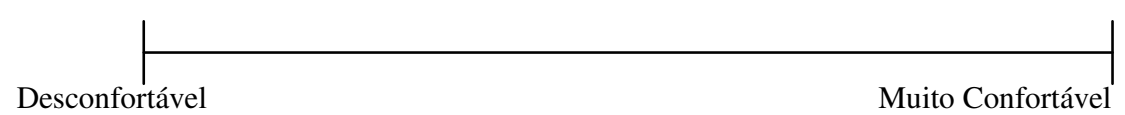

9. Conforto geral:Qual a sua percepção de conforto do tênis na sua totalidade, sem especificação de região ou material?

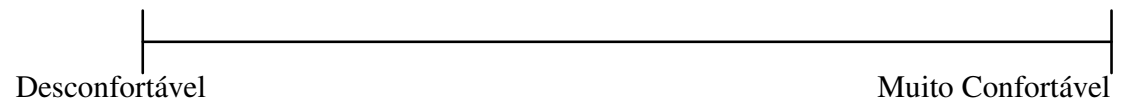




\section{REFERÊNCIAS BIBLIOGRÁFICAS}

Andrade, J. E.; Correa, A. B. Panorama da Indústria Mundial de Calçados, com Ênfase na América Latina. BNDS Setorial - Rio de Janeiro. v13: p95 - 126 p. 2001.

Bredeweg, S. W.; Kluitenberg, B.; Bessem, B.; Buist, I. Differences in kinetic variables between injured and noninjured novice runners: A prospective cohort study. J Sci Med Sport, Aug 2012.

Brueckner K.; Heidenfelder J.; Odenwald S.; Milani T. L. Mechanical and biomechanical characterization of runnig shoes with different midsole materials before and after aging. Footwear Science, v. v. 3, 2011.

Burns, J.; Crosbie, J.; Hunt, A.; Ouvrier, R. The effect of pes cavus on foot pain and plantar pressure. Clin Biomech (Bristol, Avon), v. 20, n. 9, p. 877-82, Nov 2005. ISSN 0268-0033.

Callegari-Jacques, Sidia M. Bioestatística: princípios e aplicações. Porto Alegre: Artemed, 2003. 255p.

Cavanagh, P. R.; Lafortune, M. A. Ground reaction forces in distance running. J Biomech, v. 13, n. 5, p. 397-406, 1980.

Chen H.;Nigg, N. B. Relationship between plantar pressure distribution under the foot and insole comfort Clinical Biomechanics, v. Volume 9, n. 6, p. 335-341, 1994.

Cheung, R. T.; Ng, G. Y. Influence of different footwear on force of landing during running. Phys Ther, v. 88, n. 5, p. 620-8, May 2008. ISSN 1538-6724.

Clarke, T. E.; Frederick, E. C.; Cooper, L. B. Effects of shoe cushioning upon ground reaction forces in running. Int J Sports Med, v. 4, n. 4, p. 247-51, Nov 1983b. ISSN $0172-4622$

Clarke, T. E.; Frederick, E. C.; Hamill, C. L.The effects of shoe design parameters on rearfoot control in running. Med Sci Sports Exerc, v. 15, n. 5, p. 376-81, 1983 a.

Clinghan, R.; Arnold, G. P.; Drew, T. S.; Cochrane, L. A.; Abboud, R. J. Do you get value for money when you buy an expensive pair of running shoes? Br J Sports Med, v. 42, n. 3, p. 189-93, Mar 2008. ISSN 1473-0480.

Crowell, H. P.; Davis, I. S. Gait retraining to reduce lower extremity loading in runners. Clin Biomech (Bristol, Avon), v. 26, n. 1, p. 78-83, Jan 2011.

De Wit, B.; De Clercq, D.; Aerts, P. Biomechanical analysis of the stance phase during barefoot and shod running. J Biomech, v. 33, n. 3, p. 269-78, Mar 2000.

Diss, C. E. The reliability of kinetic and kinematic variables used to analyse normal running gait. Gait Posture, v. 14, n. 2, p. 98-103, Oct 2001.

Divert, C.; Mornieux, G.; Baur, H.; Mayer, F.; Belli, A. Mechanical comparison of barefoot and shod running. Int J Sports Med, v. 26, n. 7, p. 593-8, Sep 2005.

Divert, C.; Mornieux, G.; Freychat, P.; Baly, L.; Mayer, F.; Belli, A.Barefoot-shod running differences: shoe or masseffect? Int J Sports Med, v. 29, n. 6, p. 512-8, Jun 2008. ISSN 0172-4622. 
Dixon, S. J. Use of pressure insoles to compare in-shoe loading for modern running shoes. Ergonomics, v. 51, n. 10, p. 1503-14, Oct 2008.

Feehery, R. V., JR. The biomechanics of running on different surfaces. Clin Podiatr Med Surg, v. 3, n. 4, p. 649-59, Oct 1986.

Frederick, E. C. Physiological and ergonomics factors in running shoe design. Appl Ergon, v. 15, n. 4, p. 281-7, Dec 1984. ISSN 0003-6870.

Frederick, E. C. Kinematically mediated effects of sport shoe design: a review. J Sports Sci, v. 4, n. 3, p. 169-184, 1986.

Frey, C. Footwear and stress fractures. Clin Sports Med, v. 16, n. 2, p. 249-57, Apr 1997. ISSN 0278-5919.

Hardin, E. C.; Van Den Bogert, A. J.; Hamill, J. Kinematic adaptations during running: effects of footwear, surface, and duration. Med Sci Sports Exerc, v. 36, n. 5, p. 838-44, May 2004.

Hennig, E. M.; Milani, T. L. Pressure distribution measurements for evaluation of running shoe properties. Sportverletz Sportschaden, v. 14, n. 3, p. 90-7, Sep 2000.

Hennig, E. M.; Sterzing, T. Sensitivity mapping of the human foot: thresholds at 30 skin locations. Foot Ankle Int, v. 30, n. 10, p. 986-91, Oct 2009. ISSN 1071-1007.

Hennig, E. M.; Valiant, G. A.; Liu, Q. Biomechanical variables and the perception of cushioning for running in various types of footwear. Journal of Applied Biomechanics, v. 12, n. 2, p. 143-150, May 1996.

Hohmann, E.; Imhoff, A. Epidemiology of recreational runners. Sportverletz Sportschaden, v. 17, n. 3, p. 107-11, Sep 2003.

Hong, W. H.; Lee, Y. H.; Chen, H. C.; Pei, Y. C.; Wu, C. Y. Influence of heel height and shoe insert on comfort perception and biomechanical performance of young female adults during walking. Foot Ankle Int, v. 26, n. 12, p. 1042-8, Dec 2005. ISSN 1071-1007.

Hreljac, A. Individual effects on biomechanical variables during landing in tennis shoes with varying midsole density. J Sports Sci, v. 16, n. 6, p. 531-7, Aug 1998. ISSN 0264-0414.

Hreljac, A. Impact and overuse injuries in runners. Med Sci Sports Exerc, v. 36, n. 5, p. 845-9, May 2004. ISSN 0195-9131.

James, S. L.; Bates, B. T.; Osternig, L. R. Injuries to runners. Am J Sports Med, v. 6, n. 2, p. 40-50, Mar-Apr 1978.

Jordan, C.; Payton, C.; Bartlett, R. Perceived comfort and pressure distribution in casual footwear. Clin Biomech (Bristol, Avon), v. 12, n. 3, p. S5, Apr 1997. ISSN $1879-1271$.

Lieberman, D. E.; Venkadesan, M.; Werbel, W. A.; Daoud, A. I.; D'Andrea, S.; Davis, I. S.; Mang'eni, R. O.; Pitsiladis, Y. Foot strike patterns and collision forces in habitually barefoot versus shod runners. Nature, v. 463, n. 7280, p. 531-5, Jan 28 2010 . 
Lilley, K.; Dixon, S.; Stiles, V. A biomechanical comparison of the running gait of mature and young females. Gait Posture, v. 33, n. 3, p. 496-500, Mar 2011. ISSN 1879-2219.

Macera, C. A. Lower extremity injuries in runners. Advances in prediction. Sports Med, v. 13, n. 1, p. 50-7, Jan 1992. ISSN 0112-1642.

Martin, P. E. Mechanical and physiological responses to lower extremity loading during running. Med Sci Sports Exerc, v. 17, n. 4, p. 427-33, Aug 1985. ISSN 01959131.

Mcnair, P. J.; Marshall, R. N. Kinematic and kinetic parameters associated with running in different shoes. Br J Sports Med, v. 28, n. 4, p. 256-60, Dec 1994.

Milani, T. L.; Hennig, E. M.; Lafortune, M. A. Perceptual and biomechanical variables for running in identical shoe constructions with varying midsole hardness. Clin Biomech (Bristol, Avon), v. 12, n. 5, p. 294-300, Jul 1997.

Miller, J. E.; Nigg, B. M.; Liu, W.; Stefanyshyn, D. J.; Nurse, M. A. Influence of foot, leg and shoe characteristics on subjective comfort. Foot Ankle Int, v. 21, n. 9, p. 759-67, Sep 2000. ISSN 1071-1007.

Milner, C. E.; Ferber, R.; Pollard, C. D.; Hamill, J.; Davis, I. S. Biomechanical factors associated with tibial stress fracture in female runners. Med Sci Sports Exerc, v. 38, n. 2, p. 323-8, Feb 2006. ISSN 0195-9131.

Mündermann, A.; Nigg, B. M.; Stefanyshyn, D. J.; Humble, R. N. Development of a reliable method to assess footwear comfort during running. Gait Posture, v. 16, n. 1, p. 38-45, Aug 2002.

Mündermann, A.; Stefanyshyn, D. J.; Nigg, B. M. Relationship between footwear comfort of shoe inserts and anthropometric and sensory factors. Med Sci Sports Exerc, v. 33, n. 11, p. 1939-45, Nov 2001. ISSN 0195-9131.

Nigg, B. M. The role of impact forces and foot pronation: a new paradigm. Clin J Sport Med, v. 11, n. 1, p. 2-9, Jan 2001. ISSN 1050-642X.

Nigg, B. M.; Bahlsen, H. A.; Luethi, S. M.; Stokes, S.The influence of running velocity and midsole hardness on external impact forces in heel-toe running. $\mathbf{J}$ Biomech, v. 20, n. 10, p. 951-9, 1987a. ISSN 0021-9290.

Nigg, B. M.; Morlock, M. The influence of lateral heel flare of running shoes on pronation and impact forces. Med Sci Sports Exerc,v. 19, n. 3, p. 294-302, Jun 1987. ISSN 0195-9131.

Nigg, B. M.; Stefanyshyn, D.; Cole, G.; Stergiou, P.; Miller, J. et al. The effect of material characteristics of shoe soles on muscle activation and energy aspects during running. J Biomech, v. 36, n. 4, p. 569-75, Apr 2003a. ISSN 0021-9290.

Nigg, B. M.; Stergiou, P.; Cole, G.; Stefanyshyn, D.; Mündermann, A.; Humble, N. Effect of shoe inserts on kinematics, center of pressure, and leg joint moments during running. Med Sci Sports Exerc, v. 35, n. 2, p. 314-9, Feb 2003b. ISSN 0195-9131.

Norma Brasileira ABNT NBR 14834. Conforto do Calçado, Requisitos e Ensaios. ed4. São Paulo/SP - Brasil. 2011. 
Novacheck, T. F. The biomechanics of running. Gait Posture, v. 7, n. 1, p. 77-95, 1998.

Nurse, M. A.; Hulliger, M.; Wakeling, J. M.; Nigg, B. M.; Stefanyshyn, D. J.Changing the texture of footwear can alter gait patterns. J Electromyogr Kinesiol, v. 15, n. 5, p. 496-506, Oct 2005. ISSN 1050-6411.

Perry, S. D.; Radtke, A.; Goodwin, C. R. Influence of footwear midsole material hardness on dynamic balance control during unexpected gait termination. Gait Posture, v. 25, n. 1, p. 94-8, Jan 2007. ISSN 0966-6362.

Radin, E. L.; Yang, K. H.; Riegger, C.; Kish, V. L.; O'Connor, J. J. Relationship between lower limb dynamics and knee joint pain. J Orthop Res, v. 9, n. 3, p. 398405, May 1991.

Redmond, A. C.; Crosbie, J.; Ouvrier, R. A. Development and validation of a novel rating system for scoring standing foot posture: the Foot Posture Index. Clin Biomech (Bristol, Avon), v. 21, n. 1, p. 89-98, Jan 2006.

Ryan, M. B.; Valiant, G. A.; McDonald, K.; Taunton, J. E. The effect of three different levels of footwear stability on pain outcomes in women runners: a randomised control trial. Br J Sports Med, v. 45, n. 9, p. 715-21, Jul 2011. ISSN 1473-0480.

Squadrone, R.; Gallozzi, C. Biomechanical and physiological comparison of barefoot and two shod conditions in experienced barefoot runners. J Sports Med Phys Fitness, v. 49, n. 1, p. 6-13, Mar 2009.

Taunton, J. E.;Ryan, M. B.; Clement, D. B.; McKenzie, D. C.; Lloyd-Smith, D. R. Zumbo, B. D.A retrospective case-control analysis of 2002 running injuries. Br J Sports Med, v. 36, n. 2, p. 95-101, Apr 2002. ISSN 0306-3674.

Tillman, M. D.; Fiolkowski, P.; Bauer, J. A.; Reisinger K. D.In-Shoe Plantar Measurements during Running on Different Surfaces: Changes in Temporal and Kinetic Parameters. Sports Engineering, v. 5, p. 121-128, 2002.

Van Gent, R. N.; Siem, D.; Middelkoop, M.; Van Os, A. G.; Bierma-Zeinstra, S. M.; Koes, B. W. Incidence and determinants of lower extremity running injuries in long distance runners: a systematic review. Br J Sports Med, v. 41, n. 8, p. 469-80; discussion 480, Aug 2007. ISSN 1473-0480.

Van Mechelen, W. Running injuries. A review of the epidemiological literature. Sports Med, v. 14, n. 5, p. 320-35, Nov 1992. ISSN 0112-1642.

Verdejo, R.; Mills, N. J. Heel-shoe interactions and the durability of EVA foam running-shoe midsoles. J Biomech, v. 37, n. 9, p. 1379-86, Sep 2004. ISSN 00219290 .

Wegener, C.; Burns, J.; Penkala, S. Effect of neutral-cushioned running shoes on plantar pressure loading and comfort in athletes with cavus feet: a crossover randomized controlled trial. Am J Sports Med, v. 36, n. 11, p. 2139-46, Nov 2008. ISSN 1552-3365.

Wiegerinck, J. I.; Boyd, J.; Yoder, J. C.; Abbey, A. N.; Nunley, J. A.; Queen, R. M.Differences in plantar loading between training shoes and racing flats at a selfselected running speed. Gait Posture, v. 29, n. 3, p. 514-9, Apr 2009. 


\section{APÊNDICEA - ROTINA MATLAB PARA ANÁLISE DOS DADOS DA FORÇA REAÇÃO DO SOLO}

\%Rotina elaborada para tratamento do dados da Força Reação do Solo

$\%$ Mestrado Roberto

$\% 06 / 02 / 2012$

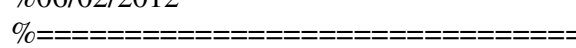

\%Limpar Variáveis e tela de comando

fclose all

clear all

clc

$\% \mathrm{p}=$ Nome do diretório selecionado

$\mathrm{p}=$ uigetdir;

$\%$ Entrar com a massa do sujeito

pc=input('qual a massa do sujeito?');

\% Multiplica pela aceleração da gravidade $\mathrm{pc}=\mathrm{pc} * 9.80665$;

$\%$ Encontra os arquivos txt no diretório $\mathrm{f}=\operatorname{dir}\left(\right.$ fullfile $\left(\mathrm{p},{ }^{\prime} \cdot{ }^{\prime}\right.$ txt') $)$;

\%Organiza a variável f para ter só os nomes de arquivo

$\mathrm{f}=$ fname;

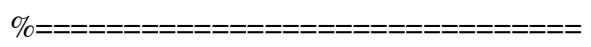

\%Calçado 1

\%Encontra os arquivos do calçado_01 c01=regexp(f,'sldldc01tldld','match');

\%Apaga as células vazias da variável c01=c01( cellfun('isempty',c01));

$\%$

$\%$ Prealocar Matrizes

$\mathrm{p} 1 \mathrm{c} 1=\operatorname{nan}(1, \operatorname{size}(\mathrm{c} 01,2)) ; \mathrm{p} 2 \mathrm{c} 1=\mathrm{p} 1 \mathrm{c} 1$;

i $1 \mathrm{c} 1=\mathrm{p} 1 \mathrm{c} 1 ; \mathrm{i} 2 \mathrm{c} 1=\mathrm{p} 1 \mathrm{c} 1$;

$\mathrm{vc} 1=\mathrm{p} 1 \mathrm{c} 1 ;$ ivc $1=\mathrm{p} 1 \mathrm{c} 1$;

itc $1=\mathrm{p} 1 \mathrm{c} 1 ; \operatorname{lrc} 1=\mathrm{p} 1 \mathrm{c} 1 ; \mathrm{tpc} 1=\mathrm{p} 1 \mathrm{c} 1$;

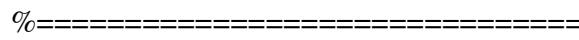

\%Loop, Carregar e Calcular Variáveis para o Calçado_01

for $\mathrm{idx}=1$ :size $(\mathrm{c} 01,2)$

$\%$ Carrega a tentativa

load(strcat(strcat(p,'''),c01 idx 1,'.txt'));

$\%$ carrega as forças da matriz na variável fz

$\mathrm{fz}=\mathrm{eval}(\mathrm{c} 01$ idx1(Nigg, 2001));

$\%$ Escolhe a coluna da frs vertical

$\mathrm{fz}=\mathrm{fz}(:, 3)$;

$\%$ Pega os valores maiores q 0

$\mathrm{fz}=\mathrm{fz}(\mathrm{fz}>7)$;

$\%$ Filtro butterworth $4^{\circ}$ ordem, corte de $300 \mathrm{~Hz}$

$[\mathrm{b}, \mathrm{a}]=\operatorname{butter}\left(4,300 / 500,{ }^{\prime}\right.$ low' $\left.^{\prime}\right)$;

$\mathrm{fz}=$ filtfilt $(\mathrm{b}, \mathrm{a}, \mathrm{fz})$;

vale $=$ zeros $($ length $(f z), 1)$;

pico=zeros(length(fz), 1$)$;

for idx2=2:length(fz)-1

\author{
if $\mathrm{fz}(\mathrm{idx} 2-1) \& \& \mathrm{fz}(\mathrm{idx} 2-$ \\ 1) $>\mathrm{fz}(\mathrm{idx} 2) \& \& \mathrm{fz}(\mathrm{idx} 2)<\mathrm{fz}(\mathrm{idx} 2+1) \& \& \mathrm{fz}(\mathrm{idx} 2+1)$ \\ vale $(\mathrm{idx} 2)=\mathrm{idx} 2$; \\ elseif fz(idx2-1)\&\&fz(idx2- \\ 1) $<\mathrm{fz}(\mathrm{idx} 2) \& \& \mathrm{fz}(\mathrm{idx} 2)>\mathrm{fz}(\mathrm{idx} 2+1) \& \& \mathrm{fz}(\mathrm{idx} 2+1)$ \\ $\operatorname{pico}(\mathrm{idx} 2)=\mathrm{idx} 2$; \\ else \\ continue \\ end \\ end \\ vale $($ vale $==0)=[]$; \\ $\operatorname{pico}($ pico $==0)=[]$; \\ try \\ p1c1(idx $)=\max (f z(\operatorname{pico}(\operatorname{pico}<\operatorname{round}(\operatorname{size}(f z, 1) / 4))))$; \\ ilc1(idx $)=$ find $(\mathrm{fz}==\mathrm{p} 1 \mathrm{c} 1(\mathrm{idx}))$; \\ p2c1(idx $)=\max (f z(p i c o($ pico $>\operatorname{round}(\operatorname{size}(f z, 1) / 4))))$; \\ $\mathrm{i} 2 \mathrm{c} 1(\mathrm{idx})=$ find $(\mathrm{fz}==\mathrm{p} 2 \mathrm{c} 1(\mathrm{idx}))$; \\ $[\operatorname{vc1}(\mathrm{idx}), \operatorname{ivc} 1(\mathrm{idx})]=\min (\mathrm{fz}(\mathrm{i} 1 \mathrm{c} 1(\mathrm{idx}): \mathrm{i} 2 \mathrm{c} 1(\mathrm{idx})))$;
}

\%encontra o mínimo e o índice entre os picos ivc $1(i d x)=i 1 c 1(i d x)+i v c 1(i d x)-1 ; \%$ soma o

índice por causa do corte na função

catch me

$\mathrm{p} 1 \mathrm{c} 1(\mathrm{idx})=\mathrm{NaN}$;

i1 1 (idx $)=\mathrm{NaN}$;

p2c1(idx $)=\max (f z($ pico $($ pico $>\operatorname{round}(\operatorname{size}(f z, 1) / 4))))$;

i $2 \mathrm{c} 1(\mathrm{idx})=$ find $(\mathrm{fz}==\mathrm{p} 2 \mathrm{c} 1(\mathrm{idx}))$;

$\operatorname{vc} 1(\mathrm{idx})=\mathrm{NaN}$;

ivc1 (idx) $=\mathrm{NaN}$;

end

\%Plotando a frs vertical filtrada

plot(fz,'k');hold on

plot(i1c1(idx),p1c1(idx),'rx','LineWidth',2,'MarkerS ize',10);

plot(i2c1(idx),p2c1(idx),'gx','LineWidth',2,'Marker Size',10);

plot(ivc1(idx),vc1(idx),'bx','LineWidth',2,'MarkerSi ze', 10);

\% pergunta se a tentativa é valida, se não eh pula a tentativa emquestão

$\mathrm{r}=$ str2double(cell2mat(inputdlg('A tentativa é válida? [1]=sim [0]=não','A escolha')));

if $r$

else

close

continue

end

close

\%encontra o máximo e o índice para até $25 \%$ do apoioCalculo do impact Transient t $80=$ round(i1c1(idx)*0.8); \%encontra $80 \%$ do tempo até o primeiro pico t20=round(i1c1(idx)*0.2); \%encontra $20 \%$ do tempo até primeiro pico 
itc $1(\mathrm{idx})=(1000 *(\mathrm{fz}(\mathrm{t} 80)-\mathrm{fz}(\mathrm{t} 20)) /(\mathrm{t} 80-\mathrm{t} 20)) / \mathrm{pc} ;$

$\%$ calcula o impacto transiente

$\%$ calcula taxa de carga

$1 \mathrm{rc} 1(\mathrm{idx})=(\mathrm{p} 1 \mathrm{c} 1(\mathrm{idx}) / \mathrm{i} 1 \mathrm{c} 1(\mathrm{idx})) * 1000 / \mathrm{pc}$;

\%normaliza o $\mathrm{p} 1$ pelo peso corporal

$\mathrm{p} 1 \mathrm{c} 1(\mathrm{idx})=\mathrm{p} 1 \mathrm{c} 1(\mathrm{idx}) / \mathrm{pc}$;

\%normaliza o p1 pelo peso corporal

$\mathrm{p} 2 \mathrm{c} 1(\mathrm{idx})=\mathrm{p} 2 \mathrm{c} 1(\mathrm{idx}) / \mathrm{pc}$;

$\mathrm{vc} 1(\mathrm{idx})=\mathrm{vc} 1(\mathrm{idx}) / \mathrm{pc}$

\%calcula a taxa de propulsão

$\operatorname{tpc} 1(\mathrm{idx})=(\mathrm{p} 2 \mathrm{c} 1(\mathrm{idx})-\mathrm{vc} 1(\mathrm{idx})) /(\mathrm{i} 2 \mathrm{c} 1(\mathrm{idx})-$

ivc1 (idx))*1000;

end

$\mathrm{p} 1 \mathrm{c} 1 \mathrm{y}=\operatorname{nan}(1, \operatorname{size}(\mathrm{c} 01,2)) ; \mathrm{p} 2 \mathrm{c} 1 \mathrm{y}=\mathrm{p} 1 \mathrm{c} 1 \mathrm{y}$;

i1c1y=p1c1y; i2c1y=p1c1y;

brc1=p1c1y; ibrc1=p1c1y;

accc1=p1c1y; acc2c1=p1c1y;

intacc $1=\mathrm{p} 1 \mathrm{c} 1 \mathrm{y}$; intbrc1=p1c1y;

for $\mathrm{idx}=1$ :size $(\mathrm{c} 01,2)$

\%carrega as forças da matriz na variável fy fy=eval(c01idx 1$)$;

$\%$ Escolhe a coluna da frs horizontal

fy=fy(:,2);

$\%$ Pega os valores maiores q 0

inicio $=$ find $(f y>1.5,1)$;

fim=find(fy<-1.5,1,'last');

fy=fy(inicio:fim);

fy=fy*-1;

$\%$ Filtro butterworth $4^{\circ}$ ordem, corte de $300 \mathrm{~Hz}$

$[\mathrm{b}, \mathrm{a}]=\operatorname{butter}\left(4,300 / 500,{ }^{\prime}\right.$ low');

fy=filtfilt(b,a,fy);

vale $=$ zeros(length(fy), 1 ;

pico=zeros(length(fy),1);

for idx $2=2$ :length(fy)-1

if fy(idx2-1)\&\&fy(idx2-

1) $>$ fy $($ idx 2$) \& \&$ fy $(i d x 2)<$ fy $(i d x 2+1) \& \&$ fy $(i d x 2+1)$

vale $(\mathrm{idx} 2)=\mathrm{idx} 2$;

elseif fy(idx2-1)\&\&fy(idx2-

1) $<$ fy $($ idx 2$) \& \& f y(i d x 2)>f y(i d x 2+1) \& \& f y(i d x 2+1)$

pico(idx2)=idx2;

else

continue

end

end

vale $($ vale $==0)=[]$;

$\operatorname{pico}(\operatorname{pico}==0)=[]$

p1cly $($ idx $)=\min (f y($ vale $))$;

i1c1y(idx $)=$ find $(f y==p 1 c 1 y(i d x))$;

p2c1y(idx $)=\max ($ fy $($ pico $))$;

i2c1y(idx $)=$ find $(f y==p 2 c 1 y(i d x))$;

$\%$ Plotando a frs horizontal filtrada

plot(fy,'k'); hold on

plot(i1c1y(idx),p1c1y(idx),'rx','LineWidth',2,'Mark

erSize',10);

plot(i2c1y(idx),p2c1y(idx),'gx','LineWidth',2,'Mark

erSize',10);

$\%$ pergunta se a tentativa é valida, se não eh pula a tentativa emquestão

r=str2double(cell2mat(inputdlg('A tentativa é

válida? [1]=sim [0]=não','A escolha')));

if $r$ else

close

continue

end

close

\%calcula a taxa de frenagem para força horizontal brc1(idx $)=(($ p1c1y(idx $)-f y(1)) / i 1 c 1 y(i d x)) * 1000$; \%calcula a máxima taxa de frenagem instantânea $\operatorname{ibrc} 1(\mathrm{idx})=\min (\operatorname{diff}(\mathrm{fy}(1: \mathrm{i} 1 \mathrm{c} 1 \mathrm{y}(\mathrm{idx})))) * 1000$;

\%calcula a taxa de propulsão para força horizontal desde o pico defrenagem até o pico de aceleração $\operatorname{accc} 1(\mathrm{idx})=((\mathrm{p} 2 \mathrm{c} 1 \mathrm{y}(\mathrm{idx})-\mathrm{p} 1 \mathrm{c} 1 \mathrm{y}(\mathrm{idx})) /(\mathrm{i} 2 \mathrm{c} 1 \mathrm{y}(\mathrm{idx})-$ i1c1y(idx)))*1000;

\%calcula taxa de propulsão para força horizontal desde o zero até o pico de aceleração [zero,izero] $=\min (\operatorname{abs}(f y(i 1 c 1 y(i d x): i 2 c 1 y(i d x))))$; izero=izero+i1c1y(idx); $\operatorname{acc} 2 \mathrm{c} 1(\mathrm{idx})=(\mathrm{p} 2 \mathrm{c} 1 \mathrm{y}(\mathrm{idx}) /(\mathrm{i} 2 \mathrm{c} 1 \mathrm{y}(\mathrm{idx})-$ izero $)) * 1000$ $\%$ calcula a integral da aceleração intaccc $1(\mathrm{idx})=\operatorname{trapz}(\mathrm{fy}(\mathrm{fy}>0))$;

$\%$ calcula a integral da frenagem intbrc1 $(\mathrm{idx})=\operatorname{trapz}(f y(f y<0))$; end

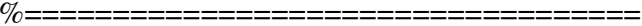

\%Calçado_02

\%Encontra os arquivos do calçado_02 c02=regexp(f,'sldldc02tldld','match'); \%Apaga as células vazias da variável c02=c02( cellfun('isempty',c02));

$\%=$

$\%$ Prealocar Matrizes

$\mathrm{p} 1 \mathrm{c} 2=\operatorname{nan}(1, \operatorname{size}(\mathrm{c} 01,2)) ; \mathrm{p} 2 \mathrm{c} 2=\mathrm{p} 1 \mathrm{c} 2$;

i1 $2=\mathrm{p} 1 \mathrm{c} 2 ; \mathrm{i} 2 \mathrm{c} 2=\mathrm{p} 1 \mathrm{c} 2$;

$\mathrm{vc} 2=\mathrm{p} 1 \mathrm{c} 2 ; \mathrm{ivc} 2=\mathrm{p} 1 \mathrm{c} 2$;

itc $2=\mathrm{p} 1 \mathrm{c} 2 ; \operatorname{lrc} 2=\mathrm{p} 1 \mathrm{c} 2 ; \operatorname{tpc} 2=\mathrm{p} 1 \mathrm{c} 2$;

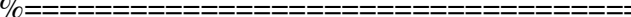

\% Loop, Carregar e Calcular Variáveis para o

Calçado_02

for idx $=1$ : $\operatorname{size}(\mathrm{c} 02,2)$

load(strcat(strcat(p, '’'),c02idx1(Nigg,

2001),'.txt'));

$\mathrm{fz}=\mathrm{eval}(\mathrm{c02}$ idx 1(Nigg, 2001));

$\mathrm{fz}=\mathrm{fz}(:, 3)$;

$\mathrm{fz}=\mathrm{fz}(\mathrm{fz}>7)$;

$[\mathrm{b}, \mathrm{a}]=$ butter $\left(4,300 / 500,{ }^{\prime}\right.$ low');

$\mathrm{fz}=$ filtfilt $(\mathrm{b}, \mathrm{a}, \mathrm{fz})$;

vale $=$ zeros $($ length(fz), 1$)$;

pico=zeros(length(fz), 1 ;

for idx2=2:length(fz)-1

if $\mathrm{fz}(\mathrm{idx} 2-1) \& \& \mathrm{fz}(\mathrm{idx} 2-$

1) $>\mathrm{fz}(\mathrm{idx} 2) \& \& \mathrm{fz}(\mathrm{idx} 2)<\mathrm{fz}(\mathrm{idx} 2+1) \& \& \mathrm{fz}(\mathrm{idx} 2+1)$

vale $(i d x 2)=i d x 2$

elseif fz(idx2-1)\&\&fz(idx2-

1) $<\mathrm{fz}(\mathrm{idx} 2) \& \& \mathrm{fz}(\mathrm{idx} 2)>\mathrm{fz}(\mathrm{idx} 2+1) \& \& \mathrm{fz}(\mathrm{idx} 2+1)$ pico(idx2)=idx2;

else

close 


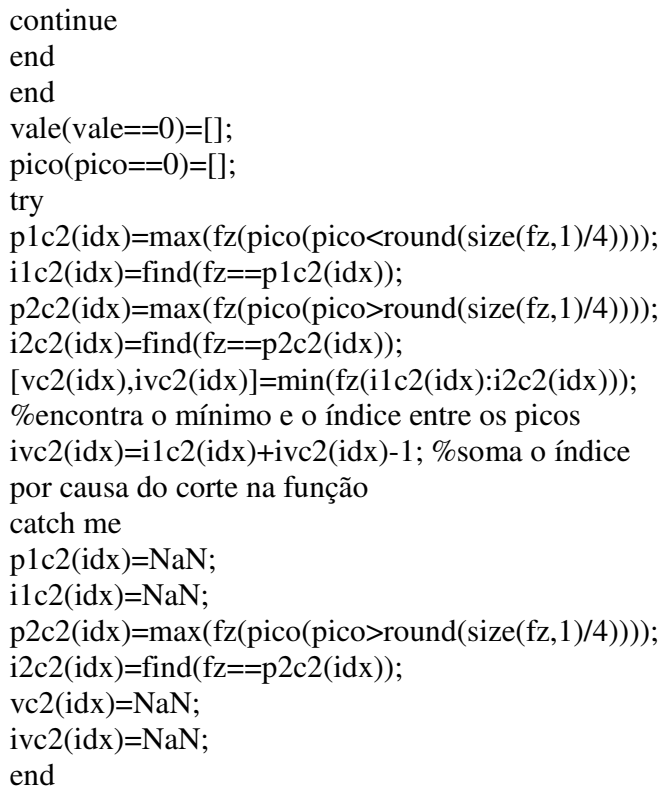

fy=fy(:,2);

\%Pega os valores maiores q 0

inicio $=$ find $(f y>1.5,1)$;

fim=find (fy<-1.5, 1,'last');

$\mathrm{fy}=\mathrm{fy}($ inicio:fim);

fy $=$ fy $*-1$

\%Filtro butterworth $4^{\circ}$ ordem, corte de $300 \mathrm{~Hz}$

[b,a]=butter(4,300/500,'low');

fy=filtfilt(b,a,fy);

vale $=$ zeros(length(fy),1);

pico=zeros(length(fy), 1 ;

for idx2=2:length(fy)-1

if fy(idx2-1)\&\&fy(idx2-

1) $>$ fy $($ idx 2$) \& \&$ fy $($ idx 2$)<f y(i d x 2+1) \& \& f y(i d x 2+1)$

vale $(\mathrm{idx} 2)=\mathrm{idx} 2$;

elseif fy(idx2-1)\&\&fy(idx2-

1) $<$ fy $($ idx 2$) \& \& f y(i d x 2)>f y(i d x 2+1) \& \& f y(i d x 2+1)$

pico(idx2)=idx2;

else

continue

end

end

$\operatorname{vale}($ vale $==0)=[]$;

$\operatorname{pico}($ pico $==0)=[]$;

p1c2y(idx $)=\min ($ fy $($ vale $))$;

i1c $2 y(i d x)=$ find $(f y==p 1 c 2 y(i d x))$;

p2c2y(idx $)=\max ($ fy $($ pico $))$;

i2c $2 y(i d x)=f i n d(f y==p 2 c 2 y(i d x))$;

\%Plotando a frs horizontal filtrada

plot(fy,'k');hold on

plot(i1c2y(idx),p1c2y(idx),'rx','LineWidth',2,'Mark erSize',10);

plot(i2c2y(idx),p2c2y(idx),'gx','LineWidth',2,'Mark erSize',10);

$\%$ pergunta se a tentativa é valida, se não eh pula a tentativa emquestão

$\mathrm{r}=$ str2double(cell2mat(inputdlg('A tentativa é

válida? [1]=sim [0]=não','A escolha')));

if $r$

else

close

continue

end

close

$\%$ calcula a taxa de frenagem para força horizontal brc2(idx $)=((p 1 c 2 y(i d x)-f y(1)) / i 1 c 2 y(i d x)) * 1000$;

\%calcula a máxima taxa de frenagem instantânea $\operatorname{ibrc} 2(\mathrm{idx})=\min (\operatorname{diff}(\mathrm{fy}(1: \mathrm{i} 1 \mathrm{c} 2 \mathrm{y}(\mathrm{idx})))) * 1000$;

\%calcula a taxa de propulsão para força horizontal desde o pico de frenagem até o pico de aceleração $\operatorname{accc} 2(\mathrm{idx})=((\mathrm{p} 2 \mathrm{c} 2 \mathrm{y}(\mathrm{idx})-\mathrm{p} 1 \mathrm{c} 2 \mathrm{y}(\mathrm{idx})) /(\mathrm{i} 2 \mathrm{c} 2 \mathrm{y}(\mathrm{idx})-$ i1c2y(idx)))*1000;

\%calcula taxa de propulsão para força horizontal desde o zero até o \%pico de aceleração

[zero,izero] $=\min (\operatorname{abs}(f y(i 1 c 2 y(i d x): i 2 c 2 y(i d x))))$; izero=izero+i1c $2 y(\mathrm{idx})$; $\operatorname{acc} 2 \mathrm{c} 2(\mathrm{idx})=(\mathrm{p} 2 \mathrm{c} 2 \mathrm{y}(\mathrm{idx}) /(\mathrm{i} 2 \mathrm{c} 2 \mathrm{y}(\mathrm{idx})-$ izero $)) * 1000$; $\%$ calcula a integral da aceleração intaccc $2(\mathrm{idx})=\operatorname{trapz}(\mathrm{fy}(\mathrm{fy}>0))$; $\%$ calcula a integral da frenagem intbrc $2(\mathrm{idx})=\operatorname{trapz}(\mathrm{fy}(\mathrm{fy}<0))$; end 


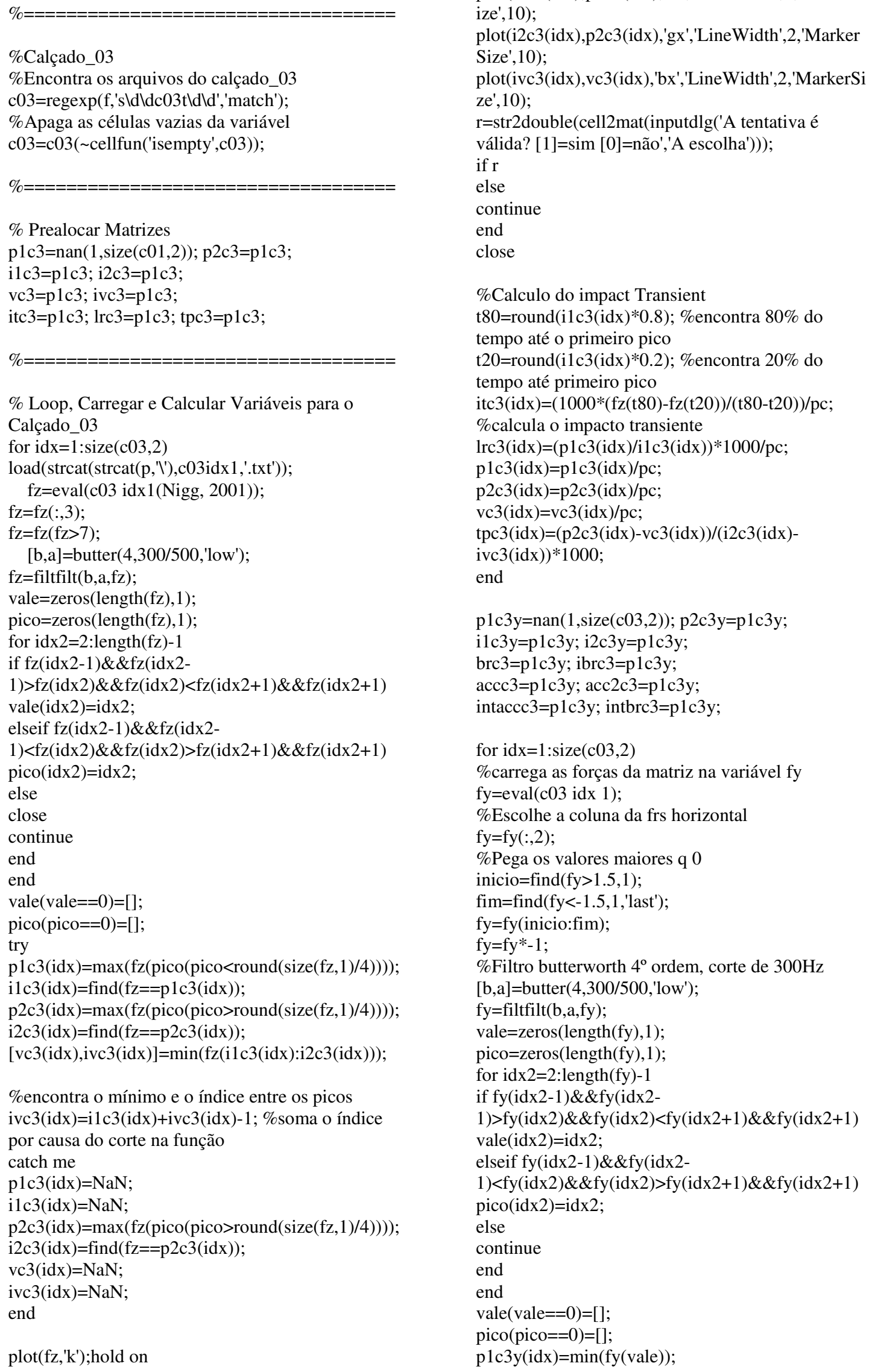

\% Loop, Carregar e Calcular Variáveis para o Calçado_03

for $\operatorname{idx}=1$ :size $(\mathrm{c} 03,2)$

load(strcat(strcat(p,'l'),c03idx1,'.txt'));

$\mathrm{fz}=\mathrm{eval}(\mathrm{c03}$ idx1(Nigg, 2001));

$\mathrm{fz}=\mathrm{fz}(:, 3)$;

$\mathrm{fz}=\mathrm{fz}(\mathrm{fz}>7)$;

[b,a]=butter(4,300/500,'low');

$\mathrm{fz}=$ filtfiltt $(\mathrm{b}, \mathrm{a}, \mathrm{fz})$;

vale $=$ zeros(length(fz), 1);

pico $=$ zeros $($ length $(f z), 1)$;

for idx2=2:length(fz)-1

if $\mathrm{fz}(\mathrm{idx} 2-1) \& \& \mathrm{fz}(\mathrm{idx} 2-$

1) $>\mathrm{fz}(\mathrm{idx} 2) \& \& \mathrm{fz}(\mathrm{idx} 2)<\mathrm{fz}(\mathrm{idx} 2+1) \& \& \mathrm{fz}(\mathrm{idx} 2+1)$

vale $(\mathrm{idx} 2)=\mathrm{idx} 2$;

elseif fz(idx2-1)\&\&fz(idx2-

1) $<\mathrm{fz}(\mathrm{idx} 2) \& \& \mathrm{fz}(\mathrm{idx} 2)>\mathrm{fz}(\mathrm{idx} 2+1) \& \& \mathrm{fz}(\mathrm{idx} 2+1)$

pico(idx2)=idx2;

else

close

continue

end

end

$\operatorname{vale}($ vale $==0)=[]$;

$\operatorname{pico}($ pico $==0)=[]$;

try

p1c3(idx $)=\max (f z($ pico $($ pico $<\operatorname{round}(\operatorname{size}(f z, 1) / 4))))$;

i1c3(idx $)=$ find $(f z==p 1 c 3(i d x))$;

$\mathrm{p} 2 \mathrm{c} 3(\mathrm{idx})=\max (\mathrm{fz}(\operatorname{pico}(\operatorname{pico}>\operatorname{round}(\operatorname{size}(\mathrm{fz}, 1) / 4))))$;

i2c3(idx) $=$ find $(f z==p 2 c 3($ idx $)$ );

[vc3(idx),ivc3(idx)]=min(fz(i1c3(idx):i2c3(idx)));

\%encontra o mínimo e o índice entre os picos ivc3(idx)=i1c3(idx)+ivc3(idx)-1; \%soma o índice por causa do corte na função

catch me

p1c3(idx) $=\mathrm{NaN}$;

i1 $3($ idx $)=\mathrm{NaN}$;

p2c3(idx $)=\max (f z($ pico $($ pico $>$ round $(\operatorname{size}(f z, 1) / 4))))$;

i2c3(idx $)=$ find $(f z==p 2 c 3($ idx $))$;

$\mathrm{vc} 3(\mathrm{idx})=\mathrm{NaN}$;

ivc3(idx) $=\mathrm{NaN}$;

end

plot(fz,'k'); hold on ize',10);

plot(i2c3(idx),p2c3(idx),'gx','LineWidth',2,'Marker

Size',10);

plot(ivc3(idx),vc3(idx),'bx','LineWidth',2,'MarkerSi ze',10);

$\mathrm{r}=\mathrm{str} 2$ double(cell2mat(inputdlg('A tentativa é

válida? [1]=sim [0]=não','A escolha')));

if $r$

else

continue

end

close

$\%$ Calculo do impact Transient

t80=round(i1c3(idx)*0.8); \%encontra $80 \%$ do tempo até o primeiro pico

t $20=$ round(i1c3(idx)*0.2); \%encontra $20 \%$ do tempo até primeiro pico

itc3 $(\mathrm{idx})=(1000 *(\mathrm{fz}(\mathrm{t} 80)-\mathrm{fz}(\mathrm{t} 20)) /(\mathrm{t} 80-\mathrm{t} 20)) / \mathrm{pc}$;

$\%$ calcula o impacto transiente

$\operatorname{lrc} 3(\mathrm{idx})=(\mathrm{p} 1 \mathrm{c} 3(\mathrm{idx}) / \mathrm{i} 1 \mathrm{c} 3(\mathrm{idx}))^{*} 1000 / \mathrm{pc}$;

$\mathrm{p} 1 \mathrm{c} 3(\mathrm{idx})=\mathrm{p} 1 \mathrm{c} 3(\mathrm{idx}) / \mathrm{pc}$;

$\mathrm{p} 2 \mathrm{c} 3(\mathrm{idx})=\mathrm{p} 2 \mathrm{c} 3(\mathrm{idx}) / \mathrm{pc}$;

$\mathrm{vc} 3(\mathrm{idx})=\mathrm{vc} 3(\mathrm{idx}) / \mathrm{pc}$;

$\operatorname{tpc} 3(\mathrm{idx})=(\mathrm{p} 2 \mathrm{c} 3(\mathrm{idx})-\mathrm{vc} 3(\mathrm{idx})) /(\mathrm{i} 2 \mathrm{c} 3(\mathrm{idx})-$

ivc3(idx))*1000;

end

$\mathrm{p} 1 \mathrm{c} 3 \mathrm{y}=\operatorname{nan}(1, \operatorname{size}(\mathrm{c} 03,2)) ; \mathrm{p} 2 \mathrm{c} 3 \mathrm{y}=\mathrm{p} 1 \mathrm{c} 3 \mathrm{y}$;

i1c $3 y=p 1 c 3 y ; i 2 c 3 y=p 1 c 3 y$;

brc3=p1c3y; ibrc3=p1c3y;

accs $3=p 1 \mathrm{c} 3 \mathrm{y} ; \operatorname{acc} 2 \mathrm{c} 3=\mathrm{p} 1 \mathrm{c} 3 \mathrm{y}$;

intaccc $3=p 1 c 3 y$; intbrc3=p1c3y;

for $\mathrm{idx}=1$ : $\operatorname{size}(\mathrm{c} 03,2)$

\%carrega as forças da matriz na variável fy

fy=eval(c03 idx 1);

$\%$ Escolhe a coluna da frs horizontal

fy=fy(:,2);

$\%$ Pega os valores maiores q 0

inicio=find $($ fy $>1.5,1)$;

fim=find(fy<-1.5,1,'last');

$f y=f y($ inicio:fim);

fy $=$ fy $*-1$;

$\%$ Filtro butterworth $4^{\circ}$ ordem, corte de $300 \mathrm{~Hz}$

[b,a]=butter(4,300/500,'low');

fy=filtfilt(b,a,fy);

vale=zeros(length(fy),1);

pico=zeros(length(fy),1);

for idx2=2:length(fy)-1

if fy(idx2-1)\&\&fy(idx2-

1) $>$ fy $($ idx 2$) \& \& f y(i d x 2)<f y(i d x 2+1) \& \& f y(i d x 2+1)$

vale $(i d x 2)=i d x 2$;

elseif fy(idx2-1)\&\&fy(idx2-

1) $<$ fy(idx2)\&\&fy(idx2)>fy(idx2+1)\&\&fy(idx2+1)

$\operatorname{pico}(\mathrm{idx} 2)=\mathrm{idx} 2$;

else

continue

end

end

vale $($ vale $==0)=[]$;

$\operatorname{pico}(\operatorname{pico}==0)=[]$;

p1c3y $(\mathrm{idx})=\min ($ fy $($ vale $))$;

plot(i1c3(idx),p1c3(idx),'rx','LineWidth',2,'MarkerS 
i1c $3 y(i d x)=$ find $(f y==p 1 c 3 y(i d x))$;

p2c3y (idx $)=\max ($ fy $($ pico $))$;

i2c3y(idx $)=$ find $(f y==p 2 c 3 y(i d x))$;

\%Plotando a frs horizontal filtrada plot(fy,'k'); hold on

plot(i1c3y(idx),p1c3y(idx),'rx','LineWidth',2,'Mark erSize',10);

plot(i2c3y(idx),p2c3y(idx),'gx','LineWidth',2,'Mark erSize',10);

$\%$ pergunta se a tentativa é valida, se não eh pula a tentativa emquestão

$\mathrm{r}=$ str2double(cell2mat(inputdlg('A tentativa é

válida? [1]=sim [0]=não','A escolha')));

if $r$

else

close

continue

end

close

\%calcula a taxa de frenagem para força horizontal $\operatorname{brc} 3(\mathrm{idx})=((\mathrm{p} 1 \mathrm{c} 3 \mathrm{y}(\mathrm{idx})-\mathrm{fy}(1)) / \mathrm{i} 1 \mathrm{c} 3 \mathrm{y}(\mathrm{idx})) * 1000$;

\%calcula a máxima taxa de frenagem instantânea $\operatorname{ibrc} 3(\mathrm{idx})=\min (\operatorname{diff}(\mathrm{fy}(1: \mathrm{i} 1 \mathrm{c} 3 \mathrm{y}(\mathrm{idx})))) * 1000$;

\%calcula a taxa de propulsão para força horizontal desde o pico de frenagem até o pico de aceleração $\operatorname{accc} 3(\mathrm{idx})=((\mathrm{p} 2 \mathrm{c} 3 \mathrm{y}(\mathrm{idx})-\mathrm{p} 1 \mathrm{c} 3 \mathrm{y}(\mathrm{idx})) /(\mathrm{i} 2 \mathrm{c} 3 \mathrm{y}(\mathrm{idx})-$ i1c3y(idx)))*1000;

\%calcula taxa de propulsão para força horizontal desde o zero até opico de aceleração

[zero,izero] $=\min (\operatorname{abs}(f y(i 1 c 3 y(i d x): i 2 c 3 y(i d x))))$; izero=izero $+\mathrm{i} 1 \mathrm{c} 3 \mathrm{y}(\mathrm{idx})$;

$\operatorname{acc} 2 \mathrm{c} 3(\mathrm{idx})=(\mathrm{p} 2 \mathrm{c} 3 \mathrm{y}(\mathrm{idx}) /(\mathrm{i} 2 \mathrm{c} 3 \mathrm{y}(\mathrm{idx})-$ izero $)) * 1000$;

\%calcula a integral da aceleração

intaccc3(idx $)=\operatorname{trapz}(f y(f y>0))$;

$\%$ calcula a integral da frenagem

intbrc3(idx $)=\operatorname{trapz}(f y(f y<0))$;

end

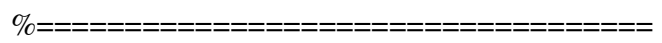

\%Calçado_04

\%Encontra os arquivos do calçado_04

c04=regexp(f,'sldldc04tldld','match');

\%Apaga as células vazias da variável

c04=c04( cellfun('isempty',c04));

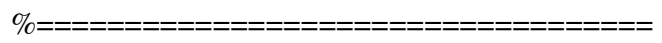

$\%$ Prealocar Matrizes

$\mathrm{p} 1 \mathrm{c} 4=\operatorname{nan}(1, \operatorname{size}(\mathrm{c} 01,2)) ; \mathrm{p} 2 \mathrm{c} 4=\mathrm{p} 1 \mathrm{c} 4$;

i1 $1 \mathrm{c} 4=\mathrm{p} 1 \mathrm{c} 4 ; \mathrm{i} 2 \mathrm{c} 4=\mathrm{p} 1 \mathrm{c} 4$;

$\mathrm{vc} 4=\mathrm{p} 1 \mathrm{c} 4 ;$ ivc4=p1c4;

itc $4=\mathrm{p} 1 \mathrm{c} 4 ; \operatorname{lrc} 4=\mathrm{p} 1 \mathrm{c} 4 ; \mathrm{tpc} 4=\mathrm{p} 1 \mathrm{c} 4$;

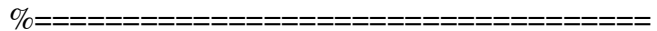

\% Loop, Carregar e Calcular Variáveis para o

Calçado_04

for $\mathrm{idx}=1: \operatorname{size}(\mathrm{c} 04,2)$

load(strcat(strcat(p,'’'),c04idx1(Nigg,

2001),'.txt'));

$\mathrm{fz}=\mathrm{eval}(\mathrm{c} 04 \mathrm{idx} 1)$;

$\mathrm{fz}=\mathrm{fz}(:, 3)$; $\mathrm{fz}=\mathrm{fz}(\mathrm{fz}>7)$;

[b,a]=butter(4,300/500,'low');

$\mathrm{fz}=$ filtfilt $(\mathrm{b}, \mathrm{a}, \mathrm{fz})$;

vale $=$ zeros $($ length $(\mathrm{fz}), 1)$;

pico $=$ zeros $($ length $(f z), 1)$;

for idx2=2:length(fz)-1

if $\mathrm{fz}(\mathrm{idx} 2-1) \& \& \mathrm{fz}(\mathrm{idx} 2-$

1) $>\mathrm{fz}(\mathrm{idx} 2) \& \& \mathrm{fz}(\mathrm{idx} 2)<\mathrm{fz}(\mathrm{idx} 2+1) \& \& \mathrm{fz}(\mathrm{idx} 2+1)$

vale $(\mathrm{idx} 2)=\mathrm{idx} 2$;

elseif fz(idx2-1)\&\&fz(idx2-

1) $<\mathrm{fz}(\mathrm{idx} 2) \& \& \mathrm{fz}(\mathrm{idx} 2)>\mathrm{fz}(\mathrm{idx} 2+1) \& \& \mathrm{fz}(\mathrm{idx} 2+1)$

pico(idx2)=idx2;

else

close

continue

end

end

$\operatorname{vale}($ vale $==0)=[]$;

$\operatorname{pico}($ pico $==0)=[]$;

try

p1c4(idx $)=\max (f z(\operatorname{pico}(\operatorname{pico}<\operatorname{round}(\operatorname{size}(f z, 1) / 4))))$;

ilc $4($ idx $)=$ find $(f z==p 1 c 4(i d x))$;

$\mathrm{p} 2 \mathrm{c} 4(\mathrm{idx})=\max (\mathrm{fz}(\operatorname{pico}(\operatorname{pico}>\operatorname{round}(\operatorname{size}(\mathrm{fz}, 1) / 4))))$;

$\mathrm{i} 2 \mathrm{c} 4(\mathrm{idx})=$ find $(\mathrm{fz}==\mathrm{p} 2 \mathrm{c} 4(\mathrm{idx}))$;

[vc4(idx),ivc4(idx)]=min(fz(i1c4(idx):i2c4(idx)));

\%encontra o mínimo e o índice entre os picos ivc4(idx)=i1c4(idx)+ivc4(idx)-1; \%soma o índice por causa do corte na função

catch me

p1c4(idx)=NaN;

ilc4(idx) $=\mathrm{NaN}$;

$\mathrm{p} 2 \mathrm{c} 4(\mathrm{idx})=\max (\mathrm{fz}(\operatorname{pico}(\operatorname{pico}>\operatorname{round}(\operatorname{size}(\mathrm{fz}, 1) / 4))))$;

$\mathrm{i} 2 \mathrm{c} 4(\mathrm{idx})=$ find $(\mathrm{fz}==\mathrm{p} 2 \mathrm{c} 4(\mathrm{idx}))$;

$\mathrm{vc} 4(\mathrm{idx})=\mathrm{NaN}$;

$\operatorname{ivc} 4(\mathrm{idx})=\mathrm{NaN}$;

end

$\operatorname{plot}\left(\mathrm{fz}, \mathrm{k}^{\prime}\right)$; hold on

plot(i1c4(idx),p1c4(idx),'rx','LineWidth',2,'MarkerS ize',10);

plot(i2c4(idx),p2c4(idx),'gx','LineWidth',2,'Marker

Size', 10);

plot(ivc4(idx),vc4(idx),'bx','LineWidth',2,'MarkerSi

ze', 10);

$\mathrm{r}=$ str2double(cell2mat(inputdlg('A tentativa é

válida? [1]=sim [0]=não','A escolha')));

if $r$

else

continue

end

close

$\%$ Calculo do impact Transient

t80=round(i1c4(idx)*0.8); \%encontra $80 \%$ do tempo até o primeiro pico

t20=round(i1c4(idx)*0.2); \%encontra $20 \%$ do

tempo até primeiro pico

itc4(idx $)=(1000 *(\mathrm{fz}(\mathrm{t} 80)-\mathrm{fz}(\mathrm{t} 20)) /(\mathrm{t} 80-\mathrm{t} 20)) / \mathrm{pc}$;

\%calcula o impacto transiente

$\operatorname{lrc} 4(\mathrm{idx})=(\mathrm{p} 1 \mathrm{c} 4(\mathrm{idx}) / \mathrm{i} 1 \mathrm{c} 4(\mathrm{idx})) * 1000 / \mathrm{pc}$;

$\mathrm{p} 1 \mathrm{c} 4(\mathrm{idx})=\mathrm{p} 1 \mathrm{c} 4(\mathrm{idx}) / \mathrm{pc}$;

$\mathrm{p} 2 \mathrm{c} 4(\mathrm{idx})=\mathrm{p} 2 \mathrm{c} 4(\mathrm{idx}) / \mathrm{pc}$;

$\mathrm{vc} 4(\mathrm{idx})=\mathrm{vc} 4(\mathrm{idx}) / \mathrm{pc}$; 
tpc4(idx $)=(\mathrm{p} 2 \mathrm{c} 4(\mathrm{idx})-\mathrm{vc} 4(\mathrm{idx})) /(\mathrm{i} 2 \mathrm{c} 4(\mathrm{idx})-$ ivc4(idx))*1000;

end

$\mathrm{p} 1 \mathrm{c} 4 \mathrm{y}=\operatorname{nan}(1, \operatorname{size}(\mathrm{c} 04,2)) ; \mathrm{p} 2 \mathrm{c} 4 \mathrm{y}=\mathrm{p} 1 \mathrm{c} 4 \mathrm{y}$;

i1 4 y=p1c4y; i2c $4 y=p 1 c 4 y$;

brc4=p1c4y; ibrc4=p1c4y;

accc $4=p 1 \mathrm{c} 4 \mathrm{y} ; \operatorname{acc} 2 \mathrm{c} 4=\mathrm{p} 1 \mathrm{c} 4 \mathrm{y}$;

intaccc $4=\mathrm{p} 1 \mathrm{c} 4 \mathrm{y}$; intbrc4=p1c4y;

for $\mathrm{idx}=1$ :size $(\mathrm{c} 04,2)$

\%carrega as forças da matriz na variável fy $\mathrm{fy}=\mathrm{eval}(\mathrm{c} 04(\mathrm{idx})(1))$

$\%$ Escolhe a coluna da frs horizontal

fy=fy(:,2);

$\%$ Pega os valores maiores q 0

inicio=find $(\mathrm{fy}>1.5,1)$;

fim=find(fy<-1.5,1,'last');

$f y=f y($ inicio:fim);

fy $=$ fy $*-1$;

$\%$ Filtro butterworth $4^{\circ}$ ordem, corte de $300 \mathrm{~Hz}$

$[\mathrm{b}, \mathrm{a}]=$ butter $\left(4,300 / 500\right.$, 'low' $^{\prime}$;

fy=filtfilt(b,a,fy);

vale $=$ zeros(length(fy),1);

pico=zeros(length(fy), 1 ;

for idx2=2:length(fy)-1

if fy(idx2-1)\&\&fy(idx2-

1) $>$ fy $($ idx 2$) \& \&$ fy $(i d x 2)<$ fy $(i d x 2+1) \& \& f y(i d x 2+1)$

vale $(\mathrm{idx} 2)=\mathrm{id} \times 2$;

elseif fy(idx2-1)\&\&fy(idx2-

1) $<$ fy $($ idx 2$) \& \& f y(i d x 2)>$ fy $(i d x 2+1) \& \&$ fy $(i d x 2+1)$

pico(idx2)=idx2;

else

continue

end

end

vale $($ vale $==0)=[]$

$\operatorname{pico}($ pico $==0)=[]$

p1c4y(idx $)=\min (f y($ vale $))$;

ilc4y(idx $)=$ find $(f y==p 1 c 4 y(i d x))$;

p $2 \mathrm{c} 4 \mathrm{y}(\mathrm{idx})=\max ($ fy $($ pico $)$;

i2c $4 y($ idx $)=$ find $(f y==p 2 c 4 y(i d x))$;

\%Plotando a frs horizontal filtrada

plot(fy,'k'); hold on

plot(i1c4y(idx),p1c4y(idx),'rx','LineWidth',2,'Mark

erSize',10)

plot(i2c4y(idx),p2c4y(idx),'gx','LineWidth',2,'Mark

erSize',10);

$\%$ pergunta se a tentativa é valida, se nao eh pula a tentativa emquestão

$\mathrm{r}=$ str2double(cell2mat(inputdlg('A tentativa é

válida? [1]=sim [0]=não','A escolha')));

if $r$

else

close

continue

end

close

$\%$ calcula a taxa de frenagem para força horizontal brc4(idx $)=((p 1 c 4 y(i d x)-f y(1)) / i 1 c 4 y(i d x)) * 1000$;

\%calcula a máxima taxa de frenagem instantânea $\operatorname{ibrc} 4(\operatorname{idx})=\min (\operatorname{diff}(f y(1: \mathrm{i} 1 \mathrm{c} 4 \mathrm{y}(\mathrm{idx})))) * 1000$; \%calcula a taxa de propulsão para força horizontal desde o pico defrenagem até o pico de aceleração $\operatorname{accc} 4(\mathrm{idx})=((\mathrm{p} 2 \mathrm{c} 4 \mathrm{y}(\mathrm{idx})-\mathrm{p} 1 \mathrm{c} 4 \mathrm{y}(\mathrm{idx})) /(\mathrm{i} 2 \mathrm{c} 4 \mathrm{y}(\mathrm{idx})-$ i1c4y(idx)) $* 1000$

\%calcula taxa de propulsão para força horizontal desde o zero até opico de aceleração

[zero,izero] $=\min (\operatorname{abs}(\mathrm{fy}(\mathrm{i} 1 \mathrm{c} 4 \mathrm{y}(\mathrm{idx}): \mathrm{i} 2 \mathrm{c} 4 \mathrm{y}(\mathrm{idx}))))$; izero=izero+i1c4y(idx);

$\operatorname{acc} 2 \mathrm{c} 4(\mathrm{idx})=(\mathrm{p} 2 \mathrm{c} 4 \mathrm{y}(\mathrm{idx}) /(\mathrm{i} 2 \mathrm{c} 4 \mathrm{y}(\mathrm{idx})-$ izero $)) * 1000$;

\%calcula a integral da aceleração

intaccc $4($ idx $)=\operatorname{trapz}(f y(f y>0))$;

$\%$ calcula a integral da frenagem

intbrc $4(i d x)=\operatorname{trapz}(f y(f y<0))$

end

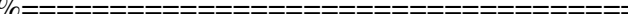

$\%$ Exportar no Excel

\%exporta uma célula com o numero do sujeito $\mathrm{s}=$ regexp(f(1),'sldld','match');

\%Cria um cabeçalho com nomes das variáveis $\mathrm{c}=\left(\right.$ ' $1^{\circ}$ Pico"ImpactoTransiente"Loading Rate'...

'2 Pico"Taxa de Propulsão'..

' 1 ${ }^{\circ}$ Pico da Força Horizontal"Taxa de

Frenagem"Taxa de Frenagem Instantânea

Máxima"Impulso Negativo'...

' $2{ }^{\circ}$ Pico da Força Horizontal"Taxa de Aceleração entre p1 e p2"Taxa de Aceleração de 0 a p2"Impulso Positivo');

$\mathrm{c}=[\mathrm{s} \mathrm{c}]$;

\%seguem diversos loops para organizar as matrizes, removendo um nível declassificação das células relevantes

for $\mathrm{idx}=1$ :size $(\mathrm{c} 01,2)$

$\mathrm{c} 01(\mathrm{idx})=\mathrm{c} 01(\mathrm{idx})(1)$;

end

ct1=regexp(c01','sld $\backslash d c \backslash d \backslash d t \backslash d \backslash d$ ','match');

for $\mathrm{idx}=1$ :size $(\mathrm{ct} 1,1)$

$\operatorname{ct} 1(\mathrm{idx})=\operatorname{ct} 1(\mathrm{idx})(1)$;

end

for $\mathrm{idx}=1$ :size $(\mathrm{c} 02,2)$

$\mathrm{c} 02(\mathrm{idx})=\mathrm{c} 02(\mathrm{idx})(1)$;

end

ct2=regexp(c02','s\d $\backslash d c \backslash d \backslash d t \backslash d \backslash d$ ','match');

for idx $=1$ :size $(\mathrm{ct} 2,1)$

$\operatorname{ct} 2(\mathrm{idx})=\operatorname{ct} 2(\mathrm{idx})(1)$;

end

for $\mathrm{idx}=1$ :size $(\mathrm{c} 03,2)$

$\mathrm{c} 03(\mathrm{idx})=\mathrm{c} 03(\mathrm{idx})(1)$;

end

ct3=regexp(c03','s\d $\backslash d c \backslash d \backslash d t \backslash d \backslash d$ ','match');

for $\mathrm{idx}=1$ :size $(\mathrm{ct} 3,1)$

ct $3(\mathrm{idx})=\mathrm{ct} 3(\mathrm{idx})(1)$;

end

for idx $=1$ :size $(\mathrm{c} 04,2)$

$\mathrm{c} 04(\mathrm{idx})=\mathrm{c} 04(\mathrm{idx})(1)$;

end

ct4=regexp(c04','sld ldcldldtldld','match');

for $\operatorname{idx}=1$ :size $(\operatorname{ct} 4,1)$

$\operatorname{ct} 4(\mathrm{idx})=\operatorname{ct} 4(\mathrm{idx})(1)$;

end

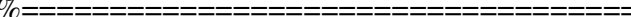


\%espaço vazio para organizar as saídas linhact=num $2 \operatorname{cell}(\operatorname{nan}(3,1))$;

\%concatena os nomes dos calçados e tentativas em blocos com a linha deespaço

ct=[ct1;linhact;ct2;linhact;ct3;linhact;ct4];

\%organiza variáveis em blocos para exportar

$\mathrm{d} 1=[\mathrm{p} 1 \mathrm{c1}$ ' itc1' lrc1' p2c1' tpc1' p1c1y' brc1' ibrc1' intbrc1' p2c1y' accc1' acc2c1' intaccc1'];

$\mathrm{d} 2=[\mathrm{p} 1 \mathrm{c} 2$ ' itc2' lrc2' p2c2' tpc2' p1c2y' brc2' ibrc2' intbrc2' p2c2y' accc2' acc2c2' intaccc2'];

d3 =[p1c3' itc3' lrc3' p2c3' tpc3' p1c3y' brc3' ibrc3' intbrc3' p2c3y' accc3' acc2c3' intaccc3'];

$\mathrm{d} 4=[\mathrm{p} 1 \mathrm{c} 4$ ' itc4' lrc4' p2c4' tpc4' p1c4y' brc4' ibrc4' intbrc4' p2c4y' acce4' acc2c4' intaccc4'];

\%Cria linhas como espaço na matriz

linha=nan $(3,13)$

\%junta os blocos e transforma em uma célula d=num2cell([d1;linha;d2;linha;d3;linha;d4]);

\%Concatena os dados com o numero de calçado e tentativa

$\mathrm{d}=[$ ct d];

\% Concatena a matriz com o cabeçalho

saida $=[\mathrm{c} ; \mathrm{d}]$;

\% Remove o aviso de que está adicionando uma nova planilha no excel

warningoffMATLAB:xlswrite:AddSheet

\%Exporta a matriz saída na aba número do sujeito para o excel

[success,message]=xlswrite('tabela_frs.xls',saida,s( 1)); 